\title{
Maintenance strategy selection: A multi-criteria group decision-making method based on cloud DEMATEL-ANP
}

Xinlong Li ( $\nabla$ xinlongl@163.com )

Chongqing University

\section{Yan Ran}

Chongqing University

Genbao Zhang

Chongqing University

Yan He

Chongqing University

\section{Research Article}

Keywords: maintenance strategy, cloud model, DEMATEL-ANP, multi-criteria decision-making, meta-action

Posted Date: February 23rd, 2022

DOl: https://doi.org/10.21203/rs.3.rs-1382908/v1

License: (c) This work is licensed under a Creative Commons Attribution 4.0 International License. Read Full License 


\title{
Maintenance strategy selection: A multi-criteria group decision-making method
}

\section{based on cloud DEMATEL-ANP}

\author{
Xinlong Li $i^{a, *}$, Yan Ran ${ }^{a}$, Genbao Zhang ${ }^{a, b, c}$, Yan $\mathrm{He}^{\mathrm{a}, \mathrm{b}}$ \\ ${ }^{a}$ College of Mechanical and Vehicle Engineering, Chongqing University, Chongqing, 400044, China \\ ${ }^{\mathrm{b}}$ State Key Laboratory Mechanical Transmission, Chongqing University, Chongqing, 400044, China \\ ${ }^{\mathrm{c}}$ College of Robot Engineering and Mechanical-Electrical Engineering, Chongqing University of Arts and Sciences, \\ Chongqing, 402160, China \\ Corresponding author: Xinlong Li (xinlongl@163.com)
}

\begin{abstract}
The selection of maintenance strategy is a very important work in maintenance engineering. Taking the meta-action unit(MU) as the research carrier, considering the randomness and fuzziness of expert evaluation and the interaction between evaluation criteria in the selection process of maintenance strategy, this paper proposes a maintenance strategy selection method based on cloud DEMATEL-ANP. Firstly, the cloud-DEMATEL model is used to establish the interaction model between the main criteria, determine the weighted cloud weight of the super matrix and the inner dependencies of the sub-criteria under the same main criteria. Then, the cloud-ANP model is used to determine the outer dependencies relationship and construct the cloud super matrix, so as to obtain the cloud weight of each evaluation criteria in maintenance strategy selection. By using the subjective and objective weighting method, the evaluation of different experts on different maintenance strategy criteria is integrated, and the priority of alternative maintenance strategies of MU is obtained. Finally, different methods are used to sort and compare the alternative maintenance strategies of the rotating body rotation MU of the CNC machine tool turntable, which verifies the scientificity and effectiveness of the method proposed in this paper are verified.
\end{abstract}

Keywords: maintenance strategy; cloud model; DEMATEL-ANP; multi-criteria decision-making; meta-action

\section{Introduction}

Maintenance is an important part of equipment management and plays a very critical role in engineering practice (Mu et al. 2021). Selecting an appropriate maintenance strategy for the equipment can not only improve the reliability and availability of the equipment, but also prolong the service life of the equipment, improve security, and ensure personal safety (Animah and Shafiee 2021; Ding and Kamaruddin 2015; Ge et al. 2017). Therefore, the maintenance strategy selection has always been a hot issue in the research of maintenance management.

According to the different degree of certainty, Ding and Kamaruddin (Ding and Kamaruddin 2015) divided the methods of optimal maintenance strategy selection into three categories. The first category is the certainty category. This type of method is usually relatively simple to use, but due to the limited criteria considered, the results obtained may not be accurate. It mainly includes Control chart(Gupta et al. 2009) and decision-making grid(Ashraf W.Labib 1998; Fernandez et al. 2003) and so on. The second category is the risk category. This type of method predicts the possible future state based on the current state information of the equipment and determines its optimal maintenance strategy. However, this type of method usually needs large amounts of calculation, time-consuming, not intuitive enough, and not convenient for application in actual engineering(Ding and Kamaruddin 2015; Özcan et al. 2017). The third category is the uncertainty category. In this type of method, the future conditions and their probabilities are unknown. Therefore, subjective judgment is needed to determine the relevant information needed to select the optimal maintenance strategy 
(Ding and Kamaruddin 2015; Özcan et al. 2017; Tersine RJ 1985). This type of method contains three sub-categories, heuristically based model(Ding et al. 2012; Waeyenbergh and Pintelon 2002, 2004), hazard-based model(Maurizio Bevilacqua et al. 2000; Dacheng Li and Gao 2010; Rosqvist et al. 2009) and multi-criteria-based model(Arjomandi et al. 2021; M. Bevilacqua and Braglia 2000; Carpitella et al. 2020; Emovon et al. 2018; Ge et al. 2017; Hemmati et al. 2018; Ighravwe and Oke 2019; Jamali et al. 2021; Lazakis and Ölçer 2016; Sadeghi and Manesh 2012). With the rapid development of multi-criteria decision-making methods, a large number of research results based on multi-criteria decision-making methods are used to select the equipment optimal maintenance strategy. Compared with other methods for determining the optimal maintenance strategy for equipment, the multi-criteria-based model is more intuitive, easy to apply, and easier to obtain more accurate results. It has become one of the most popular and effective methods to determine the optimal maintenance strategy for equipment (Özcan et al. 2017). Therefore, this paper mainly studies the method of optimal maintenance strategy selection for the equipment based on the multi-criteria-based model.

Among the research on multi-criteria decision-making methods to determine the optimal maintenance strategy for equipment, Analytic Hierarchy Process (AHP) is the most widely used. For details, see literature (Bian et al. 2018; Dey 2004; Goossens and Basten 2015; H.-C. Liu et al. 2014; Tan et al. 2011), etc. With the continuous innovation of researchers, more and more multi-criteria decision-making methods are applied to the maintenance strategy selection, such as Analytical Network Process(ANP) (Carpitella et al. 2020; Hemmati et al. 2018; Jamali et al. 2021; Sadeghi and Manesh 2012), Technique for Order Preference by Similarity to Ideal Solution(TOPSIS) (Azid 2014; Chan and Prakash 2012; Ding et al. 2014; Shyjith et al. 2008) and others hybrid methods (Animah and Shafiee 2021; Emovon et al. 2018; Ge et al. 2017; Ighravwe and Oke 2019; Kirubakaran and Ilangkumaran 2016; Liou et al. 2007; Özcan et al. 2017), etc. ANP is an extended method based on AHP. the biggest advantage of AHP is that ANP can handle the interaction between the various criteria. Decision-Making Trial and Evaluation Laboratory(DEMATEL) can visualize the interaction relationship between the criteria, and can handle the inner dependencies that ANP is not easy to handle (Aghaee and Fazli 2012). Combining DEMATEL and ANP can complement each other's advantages, simplify the number of pairwise comparisons of ANP to a certain extent, and improve the accuracy of maintenance strategy selection results. Therefore, Aghaee et al. (Aghaee and Fazli 2012) combined DEMATEL and ANP to help automobile companies choose the appropriate maintenance strategy. Recently, Arjomandi et al. (Arjomandi et al. 2021) proposed a fuzzy DEMATEL-ANP-VIKOR method to select the optimal maintenance strategy for the crude oil distillation system. Although a few of the above studies have achieved relatively good results by using DEMATEL-ANP to select the optimal maintenance strategy of equipment, there are still some main shortcomings: 1) Existing DEMATEL-ANP cannot simultaneously consider the vagueness and randomness of expert evaluation, which may lead to information loss and choose the inappropriate maintenance strategy. The cloud model (Deyi Li et al. 2009; Deyi Li and Liu 2004) was proposed by Professor Li Deyi in 1995 based on probability theory and fuzzy mathematics. It can reflect the randomness and ambiguity of things or human knowledge in the objective world, and can more vividly describe experts' uncertain evaluation of each criterion. Combining the cloud model with DEMATEL-ANP can effectively avoid the loss of information, fully consider the interaction between the criteria, and describe the relatively importance of the criteria in the form of cloud weight. However, such research has hardly been studied in the field of multi-criteria decision-making, let alone its application in the field of maintenance strategy selection. 2) The granularity of maintenance decision-making is too large. Usually, a component or system is selected as the object of the maintenance strategy selection. The decision-making made can easily lead to the phenomenon of over- or under-repair. Professor Zhang Genbao of Chongqing University proposed meta-action theory (Y. Li et al. 2021; Mu et al. 2021; Yu, Zhang, and Ran 2019; Yu, Zhang, Ran, et al. 2019), and achieved fruitful research results. The MU is the smallest motion unit of electromechanical products. Taking the MU as the maintenance decision-making object makes the decision granularity finer and facilitates the evaluation of specific criteria by experts, making the decision more accurate. At the same time, the MU is convenient for fault detection, location and analysis (X. Li, Ran, Wan, et al. 2021; X. Li, Ran, Yu, et al. 2021), which is convenient 
for systematic implementation of corresponding maintenance actions. 3) When synthesizing the opinions of multiple experts, the average value is often taken, and the subjective weight assigned to the expert by the decision maker based on the expert's working age, experience and other knowledge and the objective weight obtained by the expert's evaluation of different criteria are not well considered. This may lead to the poor aggregation of expert opinions and affect the accuracy of maintenance strategy ranking, so as to select inappropriate maintenance strategy.

Aiming at the problems existing in maintenance strategy selection, this paper takes the MU as the maintenance decision-making object, and develops a new multi-criteria group decision-making method to select the maintenance strategy for the MU. First, fully consider the ambiguity and randomness of expert evaluation, the cloud model is introduced. Then, considering the interaction between the criteria, DEMATEL-ANP is introduced, and the cloud model is combined with the DEMATEL-ANP method to obtain the cloud weight of each criterion. At the same time, the subjective and objective weighting method is developed, and the evaluation of each criterion by each expert has an independent objective weight, so as to better realize the unification of expert opinions. The rest of the paper is organized as follows: Section 2 introduces the related knowledge of the cloud model. Section 3 introduces the common maintenance policies of the MU. In Section 4, the evaluation criteria of maintenance strategy selection of MU are determined. Section 5 gives the research method of this paper. In Section 6, taking the rotating body rotation MU of CNC machine tool as an example, the optimal maintenance strategy is determined by using the method proposed in this paper. Section 7 gives the conclusions of this paper.

\section{Relevant knowledge of cloud model}

Definition 1 Cloud model(X. Li et al. 2020; Yan et al. 2009): Suppose U is a quantitative domain expressed by a numerical value, and $\mathrm{C}$ is a qualitative concept on $\mathrm{U}$. If the quantitative value $\mathrm{x}(\mathrm{x} \in \mathrm{U})$ a random realization of the qualitative concept $\mathrm{C}$, the certainty of $\mathrm{x}$ to $\mathrm{C}(\mu(x) \in[0,1])$ is a random number with a stable tendency, namely

$$
\begin{array}{r}
\mu: U \rightarrow[0,1], \\
\forall x \in U, X \rightarrow \mu(\mathrm{x})
\end{array}
$$

Then the distribution of $\mathrm{x}$ in the domain $\mathrm{U}$ is called cloud, denoted as $\mathrm{C}(\mathrm{X})$.

Definition 2 Normal cloud (Deyi Li et al. 2009; Deyi Li and Liu 2004): Let quantitative domain is U, C is a qualitative concept based on $\mathrm{U}$. If $x(x \in U)$ is a random implementation of the qualitative concept $\mathrm{C}$, and $x \sim N\left(E x, E n^{\prime 2}\right)$, where $E n^{\prime} \sim N\left(E n, H e^{2}\right)$. The certainty of $\mathrm{x}$ to C satisfies:

$$
\mu(\mathrm{x})=e^{-\frac{(x-E x)^{2}}{2 E n}}
$$

Then the distribution of $\mathrm{x}$ on the domain $\mathrm{U}$ is called a normal cloud. The distribution of normal clouds is shown in Fig. 1. 


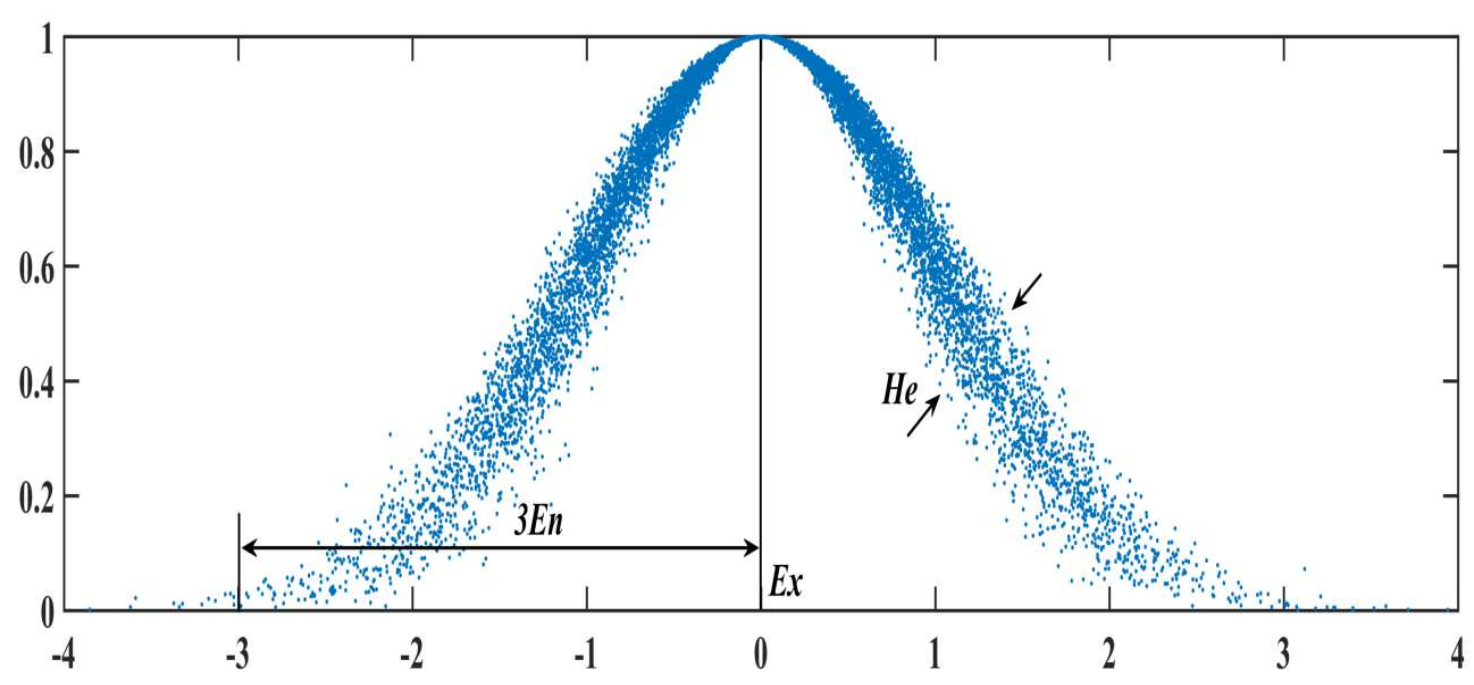

Fig. 1 Normal cloud model

Definition 3 Cloud operation: Assume that there are two normal clouds $\tilde{y}_{1} \sim \mathrm{N}\left(\mathrm{Ex}_{1}, E n_{1}, H e_{1}\right)$ and $\tilde{y}_{2} \sim \mathrm{N}\left(\mathrm{Ex}_{2}, E n_{2}, H e_{2}\right)$. The following algorithm can be obtained(X. Li et al. 2020; Wang Lihong 2013):

1) $\tilde{y}_{1}+\tilde{y}_{2}=\left(\operatorname{Ex}_{1}+\mathrm{Ex}_{2},\left(\left(E n_{1}\right)^{2}+\left(E n_{2}\right)^{2}\right)^{\frac{1}{2}},\left(\left(H e_{1}\right)^{2}+\left(H e_{2}\right)^{2}\right)^{\frac{1}{2}}\right)$;

2) $\tilde{y}_{1}-\tilde{y}_{2}=\left(\operatorname{Ex}_{1}-\mathrm{Ex}_{2},\left(\left(E n_{1}\right)^{2}+\left(E n_{2}\right)^{2}\right)^{\frac{1}{2}},\left(\left(H e_{1}\right)^{2}+\left(H e_{2}\right)^{2}\right)^{\frac{1}{2}}\right)$;

3) $\tilde{y}_{1} \times \tilde{y}_{2}=\left(\mathrm{Ex}_{1} \mathrm{Ex}_{2},\left(\left(\mathrm{Ex}_{2} E n_{1}\right)^{2}+\left(\mathrm{Ex}_{1} E n_{2}\right)^{2}\right)^{\frac{1}{2}},\left(\left(\mathrm{Ex}_{2} H e_{1}\right)^{2}+\left(\mathrm{Ex}_{1} H e_{2}\right)^{2}\right)^{\frac{1}{2}}\right)$;

4) $\frac{\tilde{y}_{1}}{\tilde{y}_{2}}=\left(\frac{\mathrm{Ex}_{1}}{\mathrm{Ex}_{2}},\left(\left(\frac{E n_{1}}{\mathrm{Ex}_{2}}\right)^{2}+\left(\frac{\mathrm{Ex}_{1} E n_{2}}{\mathrm{Ex}_{2} \mathrm{Ex}_{2}}\right)^{2}\right)^{\frac{1}{2}},\left(\left(\frac{H e_{1}}{\mathrm{Ex}_{2}}\right)^{2}+\left(\frac{\mathrm{Ex}_{1} H e_{2}}{\mathrm{Ex}_{2} \mathrm{Ex}_{2}}\right)^{2}\right)^{\frac{1}{2}}\right.$;

5) $\lambda \tilde{y}_{1}=\left(\lambda \operatorname{Ex}_{1},(\lambda)^{\frac{1}{2}} E n_{1},(\lambda)^{\frac{1}{2}} H e_{1}\right)$

6) $\frac{1}{\tilde{y}_{2}}=\left(\frac{1}{\mathrm{Ex}_{2}}, \frac{E n_{2}}{\mathrm{Ex}_{2}^{2}}, \frac{H \mathrm{e}_{2}}{\mathrm{Ex}_{2}{ }^{2}}\right)$

Definition 3 Calculation of distance between clouds(X. Li et al. 2020): Assume that there are two normal clouds $\tilde{y}_{1}=\left(\mathrm{Ex}_{1}, E n_{1}, H e_{1}\right), \tilde{y}_{2}=\left(\mathrm{Ex}_{2}, E n_{2}, H e_{2}\right)$. Then the distance between the two normal cloud is $\mathrm{d}\left(\tilde{y}_{1}, \tilde{y}_{2}\right)$.

$$
\mathrm{d}\left(\tilde{y}_{1}, \tilde{y}_{2}\right)=\left[\left(\mathrm{Ex}_{1}-\mathrm{Ex}_{1}\right)^{2}+\left(E n_{1}-E n_{2}\right)^{2}+\left(H e_{1}-H e_{2}\right)^{2}\right]^{\frac{1}{2}}
$$

Definition 3 (H. Liu et al. 2019; Shi et al. 2017) Transformation between evaluation terms and cloud: Assume that $S=\left\{s_{0}, s_{1}, \ldots, s_{r}\right\}$

$$
\tilde{y}_{0}=\left(E x_{0}, E n_{0}^{2}, H e_{0}^{2}\right), \tilde{y}_{1}=\left(E x_{1}, E n_{1}^{2}, H e_{1}^{2}\right), \ldots, \tilde{y}_{r}=\left(E x_{r}, E n_{r}^{2}, H e_{r}^{2}\right) . \text { In the effective }
$$


domain $U=\left[X_{\min }, X_{\max }\right]$, assume that a 9-scale evaluation scale is used, then the corresponding 9 clouds are as follows:

$$
\begin{aligned}
& \tilde{y}_{0}=\left(\mathrm{Ex}_{0}, E n_{0}, H e_{0}\right)=\left(X_{\min }+3 E n_{0}, \frac{E n_{1}}{0.618}, \frac{H e_{1}}{0.618}\right) \\
& \tilde{y}_{1}=\left(\mathrm{Ex}_{1}, E n_{1}, H e_{1}\right)=\left(\mathrm{Ex}_{2}-0.382\left(\mathrm{Ex}_{2}-\mathrm{Ex}_{0}\right), \frac{E n_{2}}{0.618}, \frac{H e_{2}}{0.618}\right) \\
& \tilde{y}_{2}=\left(\mathrm{Ex}_{2}, E n_{2}, H e_{2}\right)=\left(\mathrm{Ex}_{3}-0.382\left(\mathrm{Ex}_{3}-\mathrm{Ex}_{0}\right), \frac{E n_{3}}{0.618}, \frac{H e_{3}}{0.618}\right) \\
& \tilde{y}_{3}=\left(\mathrm{Ex}_{3}, E n_{3}, H e_{3}\right)=\left(\mathrm{Ex}_{4}-0.382\left(\mathrm{Ex}_{4}-\mathrm{Ex}_{0}\right), \frac{E n_{4}}{0.618}, \frac{H e_{4}}{0.618}\right) \\
& \tilde{y}_{4}=\left(\mathrm{Ex}_{4}, E n_{4}, H e_{4}\right)=\left(\frac{X_{\min }+X_{\max }}{2}, 0.382 \frac{X_{\max }-X_{\min }}{3(g+2)}, H e_{4}\right) \\
& \tilde{y}_{5}=\left(\mathrm{Ex}_{5}, E n_{5}, H e_{5}\right)=\left(\mathrm{Ex}_{4}+0.382\left(\mathrm{Ex}_{8}-\mathrm{Ex}_{4}\right), \frac{E n_{4}}{0.618}, \frac{H e_{4}}{0.618}\right) \\
& \tilde{y}_{6}=\left(\mathrm{Ex}_{6}, E n_{6}, H e_{6}\right)=\left(\mathrm{Ex}_{5}+0.382\left(\mathrm{Ex}_{8}-\mathrm{Ex}_{5}\right), \frac{E n_{6}}{0.618}, \frac{H e_{6}}{0.618}\right) \\
& \tilde{y}_{7}=\left(\mathrm{Ex}_{7}, E n_{7}, H e_{7}\right)=\left(\mathrm{Ex}_{6}+0.382\left(\mathrm{Ex}_{8}-\mathrm{Ex}_{6}\right), \frac{E n_{6}}{0.618}, \frac{H e_{6}}{0.618}\right) \\
& \tilde{y}_{8}=\left(\mathrm{Ex}_{8}, E n_{8}, H e_{8}\right)=\left(X_{\max }-3 E n_{8}, \frac{E n_{7}}{0.618}, \frac{H e_{7}}{0.618}\right)
\end{aligned}
$$

Definition 6 Comparison between clouds (C. Li et al. 2014; X. Li et al. 2020): Assume that there are two normal clouds $\tilde{y}_{1}=\left(\mathrm{Ex}_{1}, E n_{1}, H e_{1}\right)$ and $\tilde{y}_{2}=\left(\mathrm{Ex}_{2}, E n_{2}, H e_{2}\right)$ in the domain $\mathrm{U}$, Then the comparison method between $\tilde{y}_{1}$ and $\tilde{y}_{2}$ is as follows.

Firstly, convert the normal clouds $\tilde{y}_{1}$ and $\tilde{y}_{2}$ into interval numbers $y_{1}=\left[\underline{y}_{1}, \bar{y}_{1}\right]$ and $y_{2}=\left[\underline{y}_{2}, \bar{y}_{2}\right]$. $\bar{y}_{1}=E x_{1}-3 E n_{1}^{2}, \underline{y_{1}}=E x_{1}+3 E n_{1}^{2}, \bar{y}_{2}=E x_{2}-3 E n_{2}^{2}, \underline{y_{2}}=E x_{2}+3 E n_{2}^{2}, S_{y_{1}, y_{2}}=2\left(\bar{y}_{1}-\underline{\boldsymbol{y}}_{2}\right)-\left(\bar{y}_{1}-\underline{y}_{1}+\bar{y}_{2}-\underline{y}_{2}\right)$. Then:

1) If $S_{y_{1}, y_{2}}>0$, then $y_{1}>y_{2}$, it means $\tilde{y}_{1}>\tilde{y}_{2}$.

2) If $S_{y_{1}, y_{2}}=0$ and $E n_{1}^{2}<E n_{2}^{2}$, it means $\tilde{y}_{1}>\tilde{y}_{2}$.

3) If $S_{y_{1}, y_{2}}=0, E n_{1}^{2}<E n_{2}^{2}$ and $H e_{1}^{2}<H e_{2}^{2}$, that means $\tilde{y}_{1}>\tilde{y}_{2}$.

4) If $S_{y_{1}, y_{2}}=0, E n_{1}^{2}<E n_{2}^{2}$ and $H e_{1}^{2}=H e_{2}^{2}$, that means $\tilde{y}_{1}=\tilde{y}_{2}$.

Vice versa.

\section{Common maintenance policies of the MU}

As the smallest motion unit of electromechanical products, the MU mainly involves maintenance strategies including corrective maintenance (CM), time-based preventive maintenance (TBM), condition-based preventive 
maintenance (CBM) and predictive maintenance (PdM). A brief introduction to them is given below.

1. Corrective maintenance

CM(X. Li, Ran, and Zhang 2021; X. Li, Ran, Wan, et al. 2021; X. Li, Ran, Yu, et al. 2021) is a passive maintenance strategy, which is an unplanned maintenance after failure or severe performance degradation of the MU. Generally, CM can make full use of the effective life of the MU, and the maintenance cost and the technical difficulty of operation are relatively low. But because $\mathrm{CM}$ is carried out after the failure of the MU, this may cause additional downtime loss. Therefore, CM is mainly for non-critical MUs whose failure consequences are not serious.

2. Time-based preventive maintenance

TBM(X. Li, Ran, and Zhang 2021; X. Li, Ran, Wan, et al. 2021; X. Li, Ran, Yu, et al. 2021) can generally be further divided into periodic preventive maintenance and non-periodic preventive maintenance. Although non-periodic preventive maintenance can achieve better economic benefits than periodic preventive maintenance, periodic preventive maintenance is simpler and easier to implement in engineering practice. Therefore, the time-based maintenance strategy discussed in this paper specifies periodic preventive maintenance. According to the failure rules of the MU, the appropriate maintenance cycle is selected to maintain the MU. To a certain extent, TBM can overcome the defects of CM and reduce the probability of failure of the MU. However, TBM is not easy to control. If the maintenance cycle is too long, it is easy to cause under-repair, and if the maintenance cycle is too short, it is easy to cause the over-repair of the MU. TBM is not easy to control maintenance costs, resulting in a waste of maintenance resources. Therefore, TBM is mainly applicable to MUs with known failure laws.

3. Condition-based preventive maintenance

CBM(Emovon et al. 2018; X. Li, Ran, Wan, et al. 2021; X. Li, Ran, Yu, et al. 2021) monitors (manual inspection or sensor monitoring) the MU, and judges the state of the MU based on the monitored information. When the monitored performance state parameter exceeds a certain threshold, maintenance actions are taken for the MU. CBM can avoid over- and under-repair, and save maintenance resources. However, CBM has high requirements for condition monitoring and fault diagnosis and high initial investment costs, which limits its application to a certain extent.

4. Predictive maintenance

PdM (X. Li, Ran, Yu, et al. 2021; Montero Jiménez et al. 2021) is the extension of CBM. PdM not only needs to monitor the MU, but also applies Prognostics and Health Management (PHM) technology to analyze the monitored signals and obtain their development trend, so as to formulate a reasonable maintenance plan to achieve cost-effective maintenance. Compared with CBM, PdM is helpful to the reasonable allocation of maintenance resources. For some extremely important MUs with limited maintenance inventory resources, PdM is more effective. However, PdM has high technical requirements for condition monitoring, fault diagnosis and life prediction. At the same time, it also requires a lot of initial investment. 


\section{Evaluation criteria for maintenance strategy of the MU}

The selection of maintenance strategies for different MUs usually involves many evaluation criteria. The selection of evaluation criteria is very important. Under different evaluation criteria systems, the optimal maintenance strategy of the same MU may be different. Through literature research(Arjomandi et al. 2021; Carpitella et al. 2020; Chan and Prakash 2012; Emovon et al. 2018; Kirubakaran and Ilangkumaran 2016; Shyjith et al. 2008), the criteria of MU maintenance strategy evaluation considered in this paper are shown in Fig. 2.

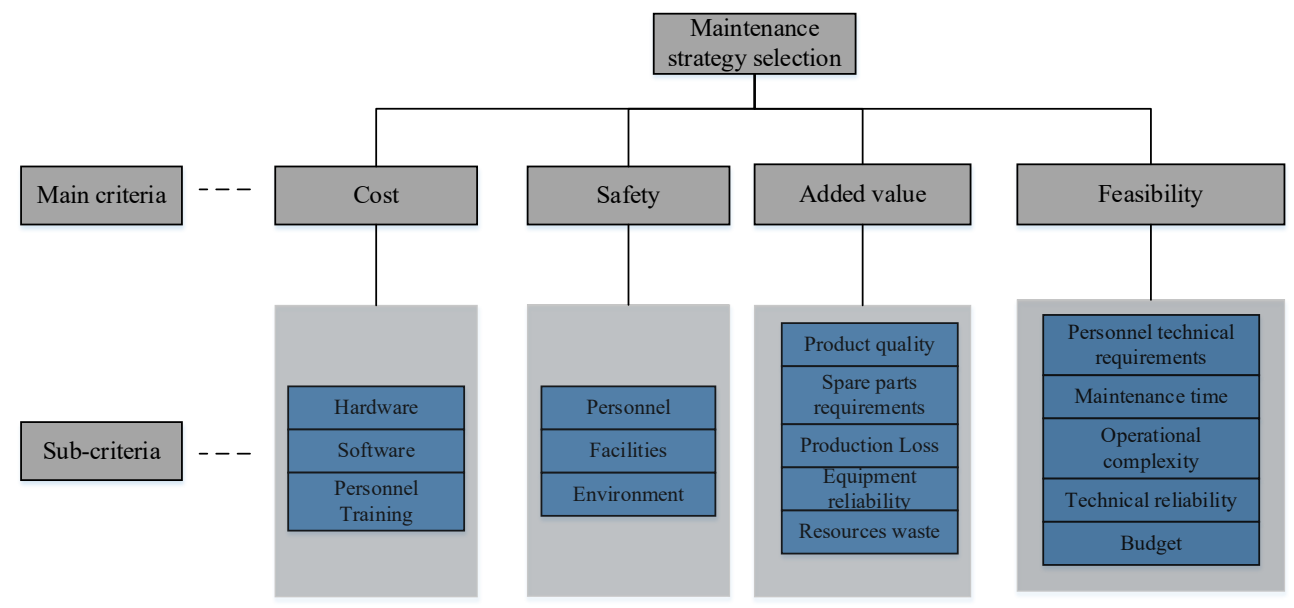

Fig.2 Evaluation criteria of maintenance strategy selection

As shown in Fig.2, the evaluation criteria of the MU include 4 main criteria and 16 sub-criteria. Details are as follows:

1) Cost: the cost of different maintenance strategies is different. Cost is an important factor that needs to be considered in maintenance strategy selection, which is mainly reflected in the following three aspects.

Hardware related cost: including equipment, materials and other related expenses required for implementing maintenance strategy.

Software related cost: for $\mathrm{CBM}$ and $\mathrm{PdM}$, relevant data monitoring system and data processing software are usually required, while CM and TBM are usually not required.

Personnel training cost: the training of maintenance personnel is essential. Different maintenance strategies have different costs for personnel training. Generally speaking, CBM and PdM not only require maintenance personnel to have basic maintenance skills, but also require maintenance personnel to master condition monitoring, data processing and other related technologies, so their personnel training costs are relatively high.

2) Safety: the safety of different maintenance strategies is different. Safety is a very critical factor that needs to be considered when selecting maintenance strategy. Safety mainly includes the following three aspects.

Personnel: the failure of the MU may lead to safety accidents and casualties, which should be specially considered when we choose the maintenance strategy. Pay special attention to failures that may cause casualties, and give priority to maintenance strategies with low failure probability.

Facilities: the failure of the MU may further damage the equipment and cause serious economic losses. Therefore, attention should also be paid to MUs that are likely to cause serious damage to the equipment.

Environment: the failure of the MU may pollute the environment, such as oil leakage.

3) Added value: the additional value brought to the factory by the application of the maintenance strategy. This paper mainly considers the following elements related to added value.

Product quality: the less the failure frequency, the more stable the equipment performance, the better the quality of the processed products and the higher the added value of the corresponding maintenance strategy. 
Spare parts requirements: the smaller the required spare parts requirements, the more convenient the management, and the higher the added value of the corresponding maintenance strategy.

Production loss: the lower the frequency of failure, the smaller the production loss, and the higher the added value of the corresponding maintenance strategy.

Equipment reliability: the less frequent failures occur, the more reliable the equipment is, the higher the added value of the corresponding maintenance strategy.

Resource waste: different maintenance strategies waste resources to different degrees. For example, CM has high utilization of parts' life and less waste of resources.

4) Feasibility: The feasibility of implementing each maintenance strategy is different. This article mainly considers the following five factors related to feasibility.

Personnel technical requirements: the higher the personnel technical requirements, the lower the feasibility of the maintenance strategy.

Maintenance time: the maintenance time required for different maintenance strategies is different. Compared with other maintenance strategies, CM does not know the specific time when the failure occurred, and there is no corresponding maintenance plan. Therefore, the maintenance time of CM is relatively longer and the feasibility is relatively lower.

Operational complexity: generally speaking, the more technologies that need to be mastered, the higher the operational complexity and the lower the feasibility. Therefore, compared with CM and TBM, CBM and PdM are less feasible.

Technical reliability: the more reliable the technology, the higher the feasibility. Related technologies of CM and TBM are simple and mature. Therefore, compared with CBM and PdM, CM and TBM have higher feasibility.

Budget: the higher the maintenance budget requirement, the lower the feasibility.

\section{Maintenance strategy selection for the MU based on cloud DEMATEL-ANP}

The flow chart of maintenance strategy selection of the MU proposed in this paper is shown in Fig.3. 


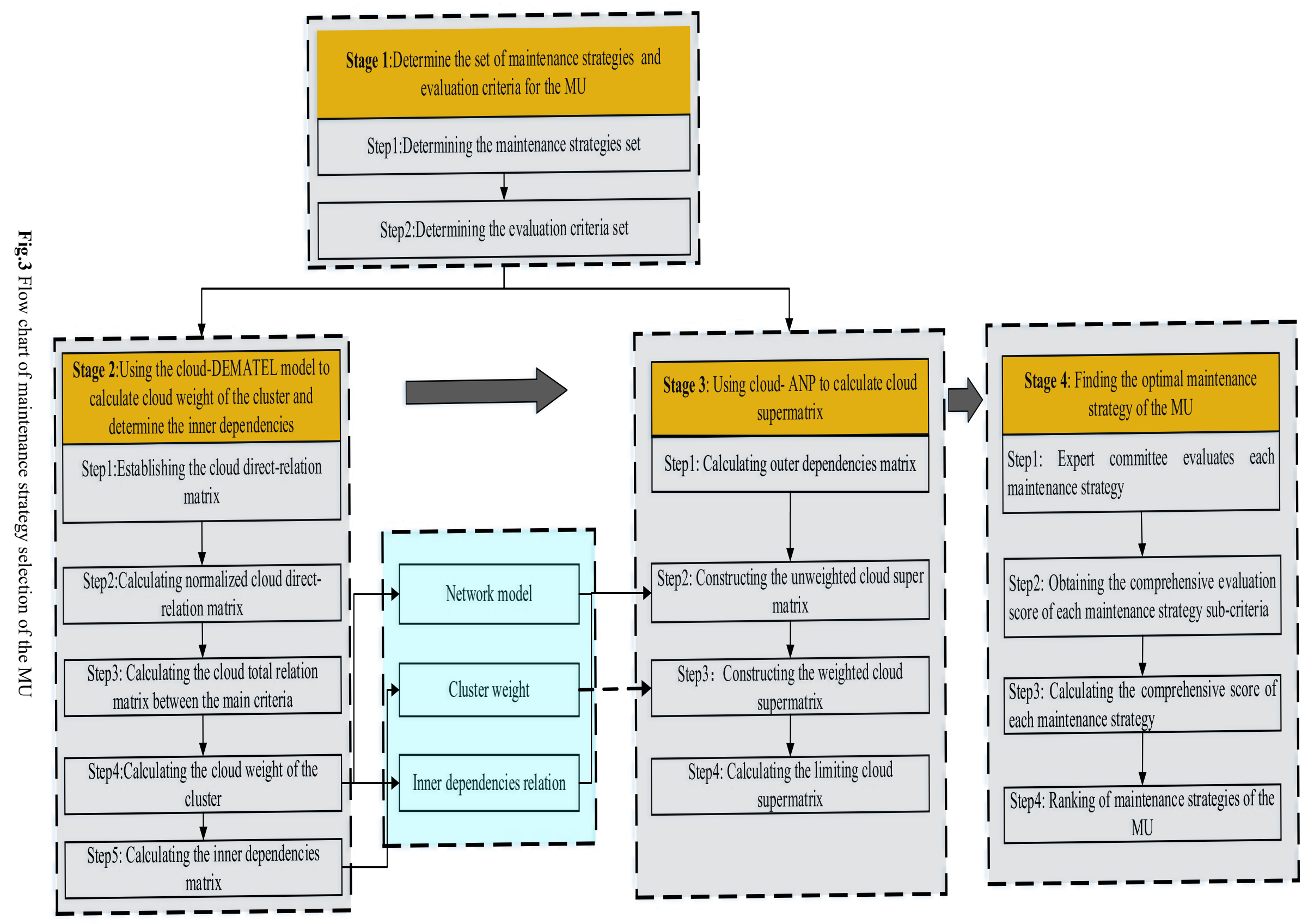




\section{Stage 1: Determining the set of maintenance strategies and evaluation criteria for the MU}

Step1: Determining the maintenance strategies set

According to the common maintenance strategies of the MU introduced in Section 3, the alternative maintenance strategy set $A=\left\{A_{1}, A_{2}, A_{3}, A_{4}\right\}$ is determined. Among them, $A_{1}$ is the CM, $A_{2}$ is the TBM, $A_{3}$ is the CBM, $A_{4}$ is the PdM.

Step2: Determining the evaluation criteria set

The main criteria set for MUs maintenance strategy selection is introduced in Section 4 . Where $C_{1}$ is cost, $C_{2}$ is safty, $\mathrm{C}_{3}$ is added value, $\mathrm{C}_{4}$ is Feasibility. $\mathrm{C}_{1}$ includes three sub-criteria, namely hardware $c_{11}$, software $c_{12}$ and personnel training $c_{13} ; \mathrm{C}_{2}$ includes three sub-criteria: personnel $c_{21}$, facilities $c_{22}$ and environment $c_{23}$; The $\mathrm{C}_{3}$ includes five sub criteria, namely product quality $c_{31}$, spare parts requirements $c_{32}$, production loss $c_{33}$, Equipment reliability $c_{34}$ and resources waste $c_{35}$; The $\mathrm{C}_{4}$ includes five sub-criteria, namely, personnel technical requirements $c_{41}$, maintenance time $c_{42}$, operational complexity $c_{43}$, technical reliability $c_{44}$ and budget $c_{45}$.

\section{Stage 2: Using the cloud-DEMATEL model to calculate cloud weight of and determine the inner dependencies}

Step1: Establishing the cloud direct-relation matrix

Suppose that $\mathrm{K}$ experts have established an expert committee to evaluate the interaction between the criteria. This paper uses 9-scale language terms to describe the degree of interaction. According to the Definition $\mathbf{5}$ in Section 2, the degree of interaction between the criteria evaluated by experts is expressed by the cloud model after term conversion. The linguistic terms evaluation scale of the degree of the interaction is shown in Tab.1.

Tab.1: Evaluation scale of interaction degree between criteria

\begin{tabular}{ccc}
\hline Linguistic terms & Code & Normal cloud representation \\
\hline None & $\mathrm{N}$ & $(2.616,0.872,0.136)$ \\
Very low & VL & $(3.179,0.539,0.084)$ \\
Low & $\mathrm{L}$ & $(3.527,0.333,0.052)$ \\
Fairly low & FL & $(4.089,0.206,0.032)$ \\
Medium & M & $(5,0.127,0.020)$ \\
Fairly high & FH & $(5.911,0.206,0.032)$ \\
High & H & $(6.473,0.333,0.052)$ \\
Very high & VH & $(6.821,0.539,0.084)$ \\
Extremely high & EH & $(7.384,0.872,0.136)$
\end{tabular}

The cloud direct-relation matrix between the main criteria formed by the expert committee is shown in the equation(1).

$$
\left\{\begin{array}{c}
\tilde{X}^{1}=\left[\tilde{x}_{i j}^{1}\right]_{4 \times 4} \\
\tilde{X}^{2}=\left[\tilde{x}_{i j}^{2}\right]_{4 \times 4} \\
\cdots \\
\tilde{X}^{K}=\left[\tilde{x}_{i j}^{K}\right]_{4 \times 4}
\end{array}\right.
$$

In previous studies, it is usually assumed that the weight of each expert is the same, and the comprehensive evaluation takes the mean value of each expert's evaluation. In this paper, the weight of expert evaluation is composed of subjective weight $\alpha$ and objective weight $\beta$, and its proportion is determined by the decision-maker. Let the subjective weight of the $k$ th expert is $w_{s}^{k}$, and the subjective weight is mainly determined according to the professional skills and the time engaged in relevant work of each expert. Decision makers score the relative working time and professional skill level of each expert to obtain the subjective weight of each expert evaluation. Assuming that the relative working time score and professional skill level score of the $k$ th expert are $S_{T}^{k}$ and $S_{P}^{k}$ respectively, then the subjective weight $w_{s}^{k}$ of the 
$k$ th expert is:

$$
w_{s}^{k}=\frac{S_{T}^{k} \cdot S_{P}^{k}}{\sum_{k=1}^{K} S_{T}^{k} \cdot S_{P}^{k}}
$$

The objective weight changes according to the evaluation of different criteria by experts. Let the normal cloud vector composed of $\mathrm{K}$ experts evaluating the influence of the $i$ th main criterion on the $j$ th main criterion is $\tilde{X}_{i j}^{\mathrm{K}}=\left(\tilde{x}_{j i}^{1}, \tilde{x}_{j i}^{2}, \ldots, \tilde{x}_{j i}^{K}\right)$, the normal cloud distance $\mathrm{d}_{\mathrm{ji}}^{\mathrm{p}, \mathrm{q}}$ between the evaluation expert $p$ and expert $q$ can be obtained by the Definition 4 in Section 2. Then the objective weight $w_{o, i j}^{k}$ of the influence of criterion $i$ on criterion $j$ evaluated by the $k$ th expert can be expressed as

$$
\left\{\begin{array}{c}
w_{o, i j}^{\mathrm{k}}=\lim \frac{1 / \sum_{\mathrm{q}=1}^{K} \mathrm{~d}_{i j}^{k, q}}{\sum_{\mathrm{p}=1}^{K}\left(1 / \sum_{\mathrm{q}=1}^{K} \mathrm{~d}_{i j}^{p, q}\right)}, q \neq k, q \neq p, k \geq 2 \\
w_{o, i j}^{\mathrm{k}}=1, k=1
\end{array}\right.
$$

When there are multiple identical evaluation results for the same object, the effective evaluation result corresponds to the one with the most evaluation times (Q), the weight of the corresponding expert is $1 / \mathrm{Q}$, and the weight of other experts is 0 ; when there are multiple evaluation results $(\mathrm{P})$ with the most number of evaluation times $(\mathrm{Q})$, the weight of the corresponding expert is $1 /(\mathrm{PQ})$, and the weight of other experts is 0 .

Through the above weighting method, the cloud direct-relation matrix $\tilde{X}$ of the main criteria after integrating the opinions of multiple experts is obtained.

$$
\tilde{X}=\left[\begin{array}{llll}
\tilde{x}_{11} & \tilde{x}_{12} & \tilde{x}_{13} & \tilde{x}_{14} \\
\tilde{x}_{21} & \tilde{x}_{22} & \tilde{x}_{23} & \tilde{x}_{24} \\
\tilde{x}_{31} & \tilde{x}_{32} & \tilde{x}_{33} & \tilde{x}_{34} \\
\tilde{x}_{41} & \tilde{x}_{42} & \tilde{x}_{43} & \tilde{x}_{44}
\end{array}\right]
$$

In the equation (4), $\tilde{x}_{i j}$ can be expressed as

$$
\tilde{x}_{i j}=\left(E x_{i j}, E n_{i j}, H e_{i j}\right)=\sum_{k=1}^{K} w_{i j}^{k} \tilde{x}_{i j}^{k}
$$

In the equation (5), $w_{i j}^{k}$ can be further expressed as

$$
\left\{\begin{array}{c}
w_{i j}^{k}=\alpha \cdot w_{s}^{k}+\beta \cdot w_{o, j j}^{k} \\
\alpha+\beta=1
\end{array}\right.
$$

Step2: Calculating normalized cloud direct-relation matrix

After the integrated cloud direct-relation matrix $\tilde{X}$ is obtained, it is further standardized to obtain the normalized cloud direct-relation matrix $\tilde{Z}$.

$$
\tilde{Z}=\left[\begin{array}{llll}
\tilde{z}_{11} & \tilde{z}_{12} & \tilde{z}_{13} & \tilde{z}_{14} \\
\tilde{z}_{21} & \tilde{z}_{22} & \tilde{z}_{23} & \tilde{z}_{24} \\
\tilde{z}_{31} & \tilde{z}_{32} & \tilde{z}_{33} & \tilde{z}_{34} \\
\tilde{z}_{41} & \tilde{z}_{42} & \tilde{z}_{43} & \tilde{z}_{44}
\end{array}\right]
$$


In the equation(7), $\tilde{z}_{i j}=\left(u_{i j}, v_{i j}, y_{i j}\right), u_{i j}, v_{i j}$ and $y_{i j}$ are the expectation, entropy and hyperentropy of $\tilde{z}_{i j}$,respectively.

$$
\left\{\begin{array}{l}
u_{i j}=E x_{i j} / \max \left(\max _{1 \leq i \leq 4} \sum_{j=1}^{4} E x_{i j}, \max _{1 \leq j \leq 4} \sum_{i=1}^{4} E x_{i j}\right) \\
v_{i j}=E n_{i j}^{2} / \max \left(\max _{1 \leq i \leq 4} \sum_{j=1}^{4} E n_{i j}^{2}, \max _{1 \leq j \leq 4} \sum_{i=1}^{4} E n_{i j}^{2}\right) \\
y_{i j}=H e_{i j}^{2} / \max \left(\max _{1 \leq i \leq 4} \sum_{j=1}^{4} H e_{i j}^{2}, \max _{1 \leq j \leq 4} \sum_{i=1}^{4} H e_{i j}^{2}\right)
\end{array}\right.
$$

Step3: Calculating the cloud total relation matrix between the main criteria

Because the elements of the normalized cloud direct-relation matrix $\tilde{Z}$ are cloud models, it can not directly obtain its inverse matrix and get the total relation matrix. Referring to the method of Gao et al. (Gao et al. 2021), $\tilde{Z}$ is divided into three matrices: expectation matrix $U$, entropy matrix $V$ and hyperentropy matrix $Y$. They can be expressed as

$$
\left\{\begin{array}{l}
U=\left[u_{i j}\right]_{4 \times 4} \\
V=\left[v_{i j}\right]_{4 \times 4} \\
Y=\left[y_{i j}\right]_{4 \times 4}
\end{array}\right.
$$

Then the total relation matrices $T^{U}, T^{V}$ and $T^{Y}$ of expectation, entropy and hyperentropy can be expressed as

$$
\left\{\begin{array}{l}
T^{U}=\left[t_{i j}^{U}\right]_{4 \times 4}=U(I-U)^{-1} \\
T^{V}=\left[t_{i j}^{V}\right]_{4 \times 4}=V(I-V)^{-1} \\
T^{Y}=\left[t_{i j}^{Y}\right]_{4 \times 4}=Y(I-Y)^{-1}
\end{array}\right.
$$

In the equation(10), $I$ is the identity matrix, $i, j \in\{1,2,3,4\}$. Because $U, V$ and $Y$ are normalized matrices, the total relation matrices $T^{U}, T^{V}$ and $T^{Y}$ exist (Grinstead C.M. and Snell J.L. 2006). The formed cloud total relation matrix can be expressed as

$$
\tilde{T}=\left[\tilde{t}_{i j}\right]=\left[\begin{array}{llll}
\tilde{t}_{11} & \tilde{t}_{12} & \tilde{t}_{13} & \tilde{t}_{14} \\
\tilde{t}_{21} & \tilde{t}_{22} & \tilde{t}_{23} & \tilde{t}_{24} \\
\tilde{t}_{31} & \tilde{t}_{32} & \tilde{t}_{33} & \tilde{t}_{34} \\
\tilde{t}_{41} & \tilde{t}_{42} & \tilde{t}_{43} & \tilde{t}_{44}
\end{array}\right]
$$

In the equation(11), $\tilde{t}_{i j}=\left(t_{i j}^{U}, t_{i j}^{V}, t_{i j}^{Y}\right)$.

Step4: Calculating the cloud weight of the cluster

Suppose the mean values of matrices $T^{U}, T^{V}$ and $T^{Y}$ are $\bar{t}_{i j}^{U}, \bar{t}_{i j}^{V}$ and $\bar{t}_{i j}^{Y}$, respectively, which constitute a cloud threshold $\delta$.

$$
\delta=\left(\bar{t}_{i j}^{U}, \bar{t}_{i j}^{V}, \bar{t}_{i j}^{Y}\right)
$$

According to Definition 6 in Section 2, compare all elements in $\tilde{T}$ with $\delta$ to form matrix S. 


$$
\left\{\begin{array}{c}
S=\left[S_{\tilde{t}_{i j}, \delta}\right]_{4 \times 4} \\
S_{\tilde{t}_{i j}, \delta}=1 \text { if } S_{\tilde{t}_{i j}, \delta}>0 \\
S_{\tilde{t}_{i j}, \delta}=0 \text { if } S_{\tilde{t}_{i j}, \delta}<0
\end{array}\right.
$$

If $S_{\tilde{t}_{i j}, \delta}=1$, it means that the main criterion $i$ has a strong influence on the main criterion $j$, and the interaction between criteria needs to be considered. If $S_{\tilde{t}_{i j}, \delta}=0$, the interaction between main criteria does not need to be considered. According to the matrix S, the network relationship model between main criteria can be obtained (Gölcük and Baykasołlu 2016).

In order to obtain the weight of cluster, a new matrix $\tilde{T}^{o}$ is formed by multiplying matrix $\mathrm{S}$ by $\tilde{T}$.

$$
\tilde{T}^{o}=\left[S_{\tilde{t}_{i j}, \delta} \cdot \tilde{t}_{i j}\right]_{4 \times 4}
$$

Sum the $i$ th row of matrix $\tilde{T}^{o}$, and we can $\operatorname{get} \tilde{T}_{i}^{o}$.

$$
\tilde{T}_{i}^{o}=\sum_{j=1}^{4} S_{\tilde{t}_{i j}, \delta} \cdot \tilde{t}_{i j}
$$

Then, the cloud weight matrix $\tilde{W}_{T}$ can be expressed as

$$
\tilde{W}_{T}=\left[E x_{i j}^{\tilde{W}_{T}}, E n_{i j}^{\tilde{W}_{T}}, H e_{i j}^{\tilde{W}_{T}}\right]_{4 \times 4}=\left[S_{\tilde{t}_{i j}, \delta} \cdot \tilde{t}_{i j} / \sum_{j=1}^{4} S_{\tilde{t}_{i j}, \delta} \cdot \tilde{t}_{i j}\right]_{4 \times 4}
$$

By normalizing $\tilde{W}_{T}$, the relative cloud weight matrix $R_{\tilde{W}_{T}}$ is obtained.

$$
R^{\tilde{W}_{T}}=\left[E x_{i j}^{\tilde{W}_{T}} / \sum_{j=1}^{4} E x_{i j}^{\tilde{W}_{T}}, E n_{i j}^{\tilde{W}_{T}} / \sum_{j=1}^{4} E n_{i j}^{\tilde{W}_{T}}, H e_{i j}^{\tilde{W}_{T}} / \sum_{j=1}^{4} H e_{i j}^{\tilde{W}_{T}}\right]_{4 \times 4}
$$

Step5: Calculating the inner dependencies matrix

When the element on the diagonal of matrix $\mathrm{S}$ is not zero, it shows that there is an inner dependence between the sub-criteria of its corresponding main criterion. At this time, the cloud total relation matrix is obtained by referring to the method of Step 1-3 in Stage 2, and the normalized cloud total relation matrix is obtained by referring to the normalization method of Step 4 in Stage 2. Thus, the inner dependencies matrix is obtained.

\section{Stage 3: Using cloud- ANP to calculate cloud supermatrix}

Step1: Using cloud-AHP to get cloud weight

For the relative weight relationship of sub-criteria under non-identical main criteria, we use the AHP-cloud model to obtain cloud weight by establishing a judgment matrix. The linguistic terms between the two criteria for expert evaluation are shown in Tab.2. 
Tab.2 Scale for evaluating relative importance between criteria

\begin{tabular}{ccc}
\hline Linguistic terms & Code & Normal cloud representation \\
\hline Equally important & E & $(2.616,0.872,0.136)$ \\
Minor important & M & $(3.179,0.539,0.084)$ \\
Moderately important & MI & $(3.527,0.333,0.052)$ \\
Important & I & $(4.089,0.206,0.032)$ \\
Quite important & QI & $(5,0.127,0.020)$ \\
Strongly important & SI & $(5.911,0.206,0.032)$ \\
Very important & VI & $(6.473,0.333,0.052)$ \\
Very strongly important & VSI & $(6.821,0.539,0.084)$ \\
Extremely important & EI & $(7.384,0.872,0.136)$ \\
\hline
\end{tabular}

Assuming that the cloud judgment matrix of the $k$ th expert is $\tilde{W}^{k}$, then $\tilde{W}^{k}$ can be expressed as

$$
\tilde{W}^{k}=\left[\begin{array}{cccc}
\tilde{w}_{11}^{k} & \tilde{w}_{12}^{k} & \ldots & \tilde{w}_{1 n}^{k} \\
\tilde{w}_{21}^{k} & \tilde{w}_{22}^{k} & \ldots & \tilde{w}_{2 n}^{k} \\
\ldots & \ldots & \ldots & \ldots \\
\tilde{w}_{n 1}^{k} & \tilde{w}_{n 2}^{k} & \ldots & \tilde{w}_{n n}^{k}
\end{array}\right]_{n \times n}
$$

In the equation(18), the diagonal elements $\tilde{w}_{i i}^{k}=(1,0,0)$, and $\tilde{w}_{j i}^{k}=1 / \tilde{w}_{i j}^{k}$. Referring to the subjective and objective weighting method in Stage 2, the integrated cloud judgment matrix $\tilde{W}$ is obtained, which can be expressed as

$$
\tilde{W}=\left[\begin{array}{cccc}
\tilde{w}_{11} & \tilde{w}_{12} & \ldots & \tilde{w}_{1 n} \\
\tilde{w}_{21} & \tilde{w}_{22} & \ldots & \tilde{w}_{2 n} \\
\ldots & \ldots & \ldots & \ldots \\
\tilde{w}_{n 1} & \tilde{w}_{n 1} & \ldots & \tilde{w}_{n n}
\end{array}\right]_{n \times n}
$$

In the equation(19), $\tilde{w}_{i j}=\left(E x^{\tilde{w}_{i j}}, E n^{\tilde{w}_{i j}}, H e^{\tilde{w}_{i j}}\right)$

Referring to literature (Jia and Xu 2014; Tiejun and Yundong 2016), the cloud weight vector $\left(\tilde{A}_{1}=\left(\tilde{a}_{1}, \tilde{a}_{2}, \ldots, \tilde{a}_{n}\right)\right.$, $\left.\tilde{a}_{i}=\left(E x^{\tilde{a}_{i}}, E n^{\tilde{a}_{i}}, H e^{\tilde{a}_{i}}\right), i \in\{1,2, \ldots, n\}\right)$ of the criterion is calculated by the square root method. Then the cloud weight expectation $E x^{\tilde{a}_{i}}$, entropy $E n^{\tilde{a}_{i}}$ and hyperentropy $H e^{\tilde{a}_{i}}$ of the $i$ th criterion can be expressed as 


$$
\left\{\begin{array}{c}
E x^{\tilde{w}_{i}}=\frac{\left(\prod_{j=1}^{n} E x^{\tilde{w}_{i j}}\right)^{1 / n}}{\sum_{i=1}^{n}\left(\prod_{j=1}^{n} E x^{\tilde{w}_{i j}}\right)^{1 / n}}=\frac{\left[\left(\prod_{j=1}^{n} E x^{\tilde{w}_{i j}}\right)^{1 / n} \cdot\left(\sum_{j=1}^{n}\left(\frac{E n^{\tilde{w}_{i j}}}{E x^{\tilde{w}_{i j}}}\right)^{2}\right)^{1 / 2}\right]^{1 / n}}{\sum_{i=1}^{n}\left[\left(\prod_{j=1}^{n} E x^{\tilde{w}_{i j}}\right)^{1 / n} \cdot\left(\sum_{j=1}^{n}\left(\frac{E n^{\tilde{w}_{i j}}}{E x^{\tilde{w}_{i j}}}\right)^{2}\right)^{1 / 2}\right]^{1 / n}} \\
H e^{\tilde{w}_{i}}=\frac{\left[\left(\prod_{j=1}^{n} E x^{\tilde{w}_{i j}}\right)^{1 / n} \cdot\left(\sum_{j=1}^{n}\left(\frac{H e^{\tilde{w}_{i j}}}{E x^{\tilde{w}_{i j}}}\right)^{2}\right)^{1 / 2}\right]^{1 / n}}{\sum_{i=1}^{n}\left[\left(\prod_{j=1}^{n} E x^{\tilde{w}_{i j}}\right)^{1 / n} \cdot\left(\sum_{j=1}^{n}\left(\frac{H e^{\tilde{w}_{i j}}}{E x^{\tilde{w}_{i j}}}\right)^{2}\right)^{1 / 2}\right]^{1 / n}}
\end{array}\right.
$$

Referring to Yang et.al (Yang et al. 2013), the consistency index CI of computing cloud judgment matrix is shown in the equation(21).

$$
C I=\frac{1}{n(n-1)} \sum_{\substack{i, j=1 \\ i \neq j}}^{n}\left(\frac{H e^{\tilde{w}_{i j}}}{E x^{\tilde{w}_{i j}}}\right)
$$

In the equation(21), $n$ is the dimension of the cloud judgment matrix. Generally, the smaller the $C I$ is, the higher the consistency is. In practice, $C I<0.1$ is usually required.

Step2: Constructing the unweighted cloud supermatrix

The inner dependencies matrix obtained in Step5 of Stage 2 is transposed and place it in the corresponding position in the supermatrix. At the same time, the relative cloud weight obtained by the cloud-AHP is also placed in the corresponding position of the supermatrix. For the specific method, refer to the literature (Gölcük and Baykasollu 2016) to form an unweighted cloud super matrix $\tilde{W}^{S}$.

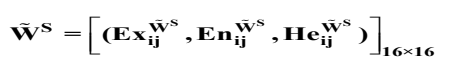

$$
\begin{aligned}
& \mathrm{C}_{1} \quad \mathrm{C}_{2} \quad \mathrm{C}_{3} \quad \mathrm{C}_{3}
\end{aligned}
$$

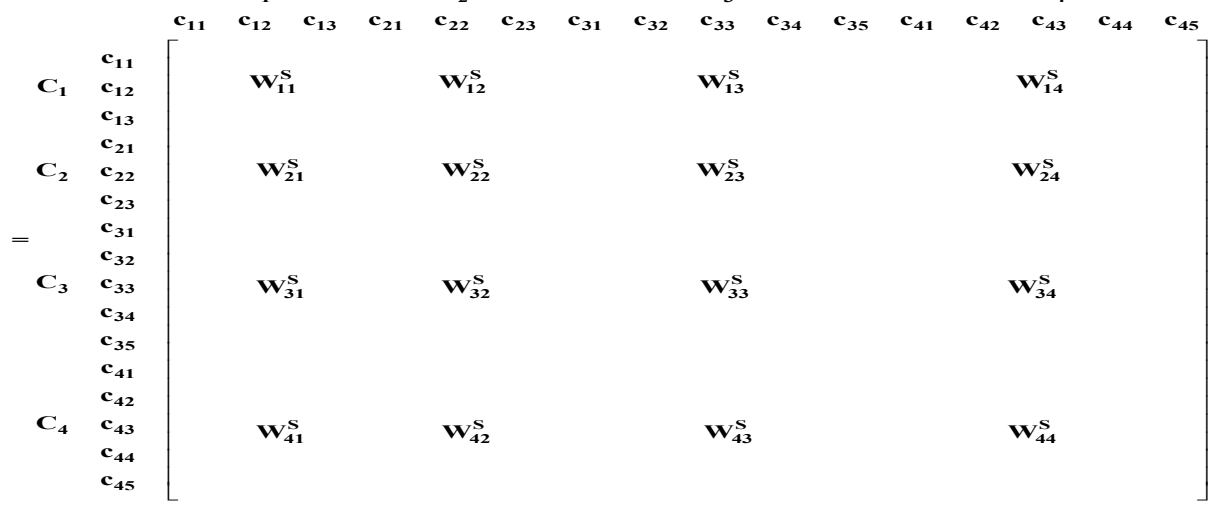


In the equation (22), $W_{i i}^{S}(i=1,2,3,4)$ is the transposed matrix of the corresponding inner dependencies matrix.

Step3: Constructing the weighted cloud supermatrix

$R^{\tilde{W}_{T}}$ obtained in Stage 2 is transposed and multiply it by the corresponding block matrix in the equation (22) to obtain matrix $\tilde{W}^{W} \cdot \tilde{W}^{W}$ can be expressed as

$$
\tilde{W}^{W}=\left[\begin{array}{cccc}
R_{11}^{\tilde{W}_{T}} \cdot W_{11}^{S} & R_{12}^{\tilde{W}_{T}} \cdot W_{12}^{S} & R_{13}^{\tilde{W}_{T}} \cdot W_{13}^{S} & R_{14}^{\tilde{W}_{T}} \cdot W_{14}^{S} \\
R_{21}^{\tilde{W}_{T}} \cdot W_{21}^{S} & R_{22}^{\tilde{W}_{T}} \cdot W_{22}^{S} & R_{23}^{\tilde{W}_{T}} \cdot W_{23}^{S} & R_{24}^{\tilde{W}_{T}} \cdot W_{24}^{S} \\
R_{31}^{\tilde{W}_{T}} \cdot W_{31}^{S} & R_{32}^{\tilde{W}_{T}} \cdot W_{32}^{S} & R_{33}^{\tilde{W}_{T}} \cdot W_{33}^{S} & R_{34}^{\tilde{W}_{T}} \cdot W_{34}^{S} \\
R_{41}^{\tilde{W}_{T}} \cdot W_{41}^{S} & R_{42}^{\tilde{W}_{T}} \cdot W_{42}^{S} & R_{43}^{\tilde{W}_{T}} \cdot W_{43}^{S} & R_{44}^{\tilde{W}_{T}} \cdot W_{44}^{S}
\end{array}\right]
$$

According to the relative cloud weight calculation method in Stage 2, each column of the block matrix in equation (23) is normalized to obtain the normalized cloud weight matrix $\tilde{W}^{N}$.

$$
\tilde{W}^{N}=\left[\left(E x_{i j}^{\tilde{W}^{N}}, E n_{i j}^{\tilde{W}^{N}}, H e_{i j}^{\tilde{W}^{N}}\right)\right]_{16 \times 16}
$$

Step4: Calculating the cloud limiting supermatrix

Matrix $\tilde{W}^{N}$ is divided into matrices $B_{1}, B_{2}$ and $B_{3}$ composed of expectation, entropy and hyperentropy of its elements.

$$
\left\{\begin{array}{l}
B_{1}=\left[E x_{i j}^{\tilde{W}^{N}}\right]_{16 \times 16} \\
B_{2}=\left[E n_{i j}^{\tilde{W}^{N}}\right]_{16 \times 16} \\
B_{3}=\left[H e_{i j}^{\tilde{W}^{N}}\right]_{16 \times 16}
\end{array}\right.
$$

The corresponding hypermatrices $O, P$ and $Q$ of the matrices $B_{1}, B_{2}$ and $B_{3}$ are obtained, respectively.

$$
\left\{\begin{array}{l}
O=\lim _{l \rightarrow \infty} B_{1}{ }^{l}=\left[o_{i j}\right]_{16 \times 16} \\
P=\lim _{l \rightarrow \infty} B_{2}{ }^{l}=\left[p_{i j}\right]_{16 \times 16} \\
Q=\lim _{l \rightarrow \infty} B_{3}{ }^{l}=\left[q_{i j}\right]_{16 \times 16}
\end{array}\right.
$$

Finally, the cloud limiting supermatrix $\tilde{W}^{C}$ is obtained by combining the corresponding position elements of matrices $O, P$ and $Q$.

$$
\tilde{W}^{C}=\left[\left(o_{i j}, p_{i j}, q_{i j}\right)\right]_{16 \times 16}
$$

The column of matrix $\tilde{W}^{C}$ is the cloud weight vector $\tilde{W}^{B}$ of each sub criterion.

$$
\tilde{W}^{B}=\left\{\tilde{w}_{1}^{b}, \tilde{w}_{2}^{b}, \ldots, w_{16}^{b}\right\}
$$

\section{Stage 4:Finding the optimal maintenance of the MU}

\section{Step1: Expert committee evaluates each maintenance strategy}

The expert committee scores various criteria of different maintenance strategies, and the criterion scoring scale is shown in Tab.3. 
Tab.3 criteria scoring scale (the better the criterion is, the higher the score is)

\begin{tabular}{lll}
\hline Linguistic terms & Code & Normal cloud representation \\
\hline None & $\mathrm{N}$ & $(2.616,0.872,0.136)$ \\
Very low & $\mathrm{VL}$ & $(3.179,0.539,0.084)$ \\
Low & $\mathrm{L}$ & $(3.527,0.333,0.052)$ \\
Fairly low & FL & $(4.089,0.206,0.032)$ \\
Medium & $\mathrm{M}$ & $(5,0.127,0.020)$ \\
Fairly high & $\mathrm{FH}$ & $(5.911,0.206,0.032)$ \\
High & $\mathrm{H}$ & $(6.473,0.333,0.052)$ \\
Very high & $\mathrm{VH}$ & $(6.821,0.539,0.084)$ \\
Extremely high & $\mathrm{EH}$ & $(7.384,0.872,0.136)$ \\
\hline
\end{tabular}

Step2: Obtaining the comprehensive evaluation score of each maintenance strategy sub-criteria

The subjective and objective weighting method of Stage 2 is still used, and the expert evaluation results are integrated so as to obtain the comprehensive score of each sub-criteria of the four maintenance strategies.

$$
\tilde{S}^{A_{i}}=\left\{\tilde{s}_{1}^{A_{i}}, \tilde{s}_{2}^{A_{i}}, \ldots, \tilde{s}_{16}^{A_{i}}\right\}
$$

In the equation (29), $i=1,2,3,4 . A_{i}$ represents the $i$ th maintenance strategy.

Step3: Calculating the comprehensive score of each maintenance strategy

The cloud weight vector $\tilde{W}^{B}$ of the sub-criteria obtained in Stage 3 is respectively multiplied by the corresponding four maintenance strategy sub-criteria score vectors $\tilde{S}^{A_{i}}$ to obtain the comprehensive score cloud value $\tilde{S}_{\text {total }}^{A_{i}}$ of each maintenance strategy.

$$
\tilde{S}_{\text {total }}^{A_{i}}=\tilde{W}^{B} \cdot \tilde{S}^{A_{i}}, i=1,2,3,4
$$

Step4: Ranking of maintenance strategies of the MU

According to the Definition 6 in Section 2, the comprehensive scores of the four maintenance strategies are compared and sorted to obtain the optimal maintenance strategy of the MU.

\section{Case study}

\subsection{Problem description}

The turntable is a key component of the CNC machine tools, its structure diagram is shown in Fig.4(X. Li et al. 2020; Mengsheng 2018).

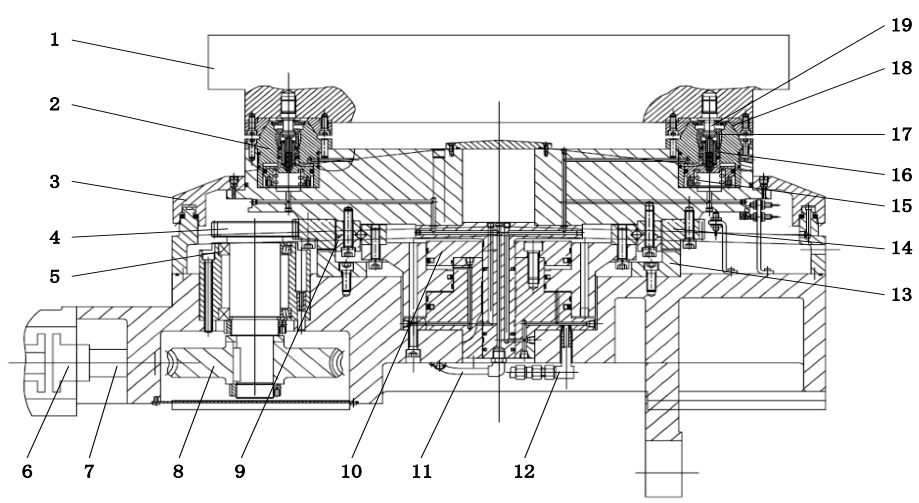


Fig.4 The structure diagram of turntable of the CNC machine tools

1. Plate 2. Male tapper 3. Sealed housing 4. Gear shaft 5. Gear shaft bearing 6. Motor 7. Worm 8. Worm wheel 9. Rotary body bearing 10. Lift cylinder 11. Locking cylinder oil circuit 12. Lift cylinder oil circuit 13. Lower tooth disc 14. Rotating body 15 . Large spring 16. Pull stud 17 . Claw 18. Female tapper 19. Positioning nail

The CNC turntable contains dozens of parts. Usually, the entire CNC turntable is used as the decision-making object, it appears too rough and the decision-making is not accurate enough. Wang Yang (Wang Yang 2018) obtained 12 MUs through FMA(function-motion-action) decomposition of the CNC turntable. Among them, the rotating body rotation MU is a very important MU, and its structure diagram is shown in Fig.5. This paper takes the rotating body rotation MU of the turntable as an example to determine the best maintenance strategy of it.

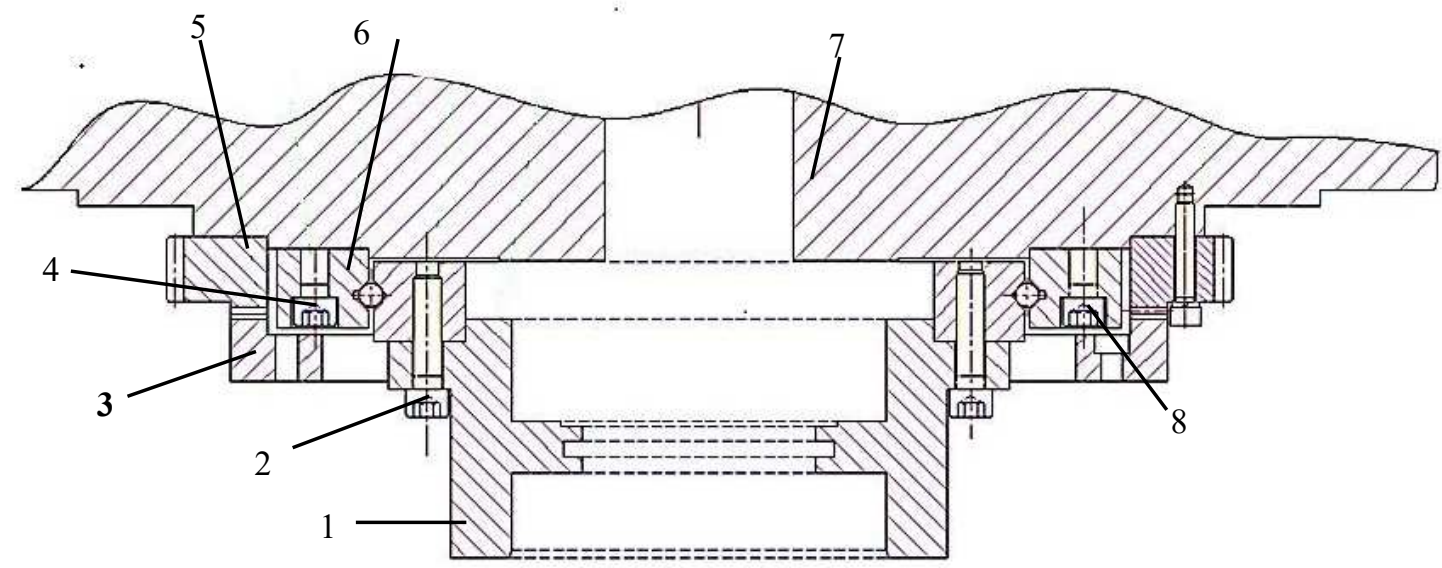

Fig.5 The structure diagram of rotating body rotation MU

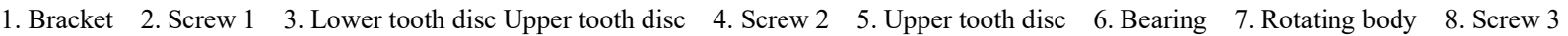

6.2 Maintenance strategies ranking of the rotating body rotation MU

Stage 1: Determining the set of maintenance strategies and evaluation criteria for the rotating body rotation MU

In the Sections 3 and 4 of this paper, the maintenance strategy set and evaluation criterion set of the rotating body rotation $\mathrm{MU}$ are determined respectively.

\section{Stage 2: Using the cloud-DEMATEL model to calculate cloud weight of and determine the inner dependencies}

In this paper, three experts are invited to evaluate the interaction between the main criteria of maintenance strategy evaluation, and the evaluation table is shown in Tab.4.

Tab.4 Experts' evaluation of the interaction between the main criteria

\begin{tabular}{lllll}
\hline Expert 1/ Expert 2/ Expert 3 & $\mathrm{C}_{1}$ & $\mathrm{C}_{2}$ & $\mathrm{C}_{3}$ & $\mathrm{C}_{4}$ \\
\hline $\mathrm{C}_{1}$ & $/$ & $\mathrm{H} / \mathrm{VH} / \mathrm{H}$ & $\mathrm{H} / \mathrm{VH} / \mathrm{M}$ & $\mathrm{H} / \mathrm{H} / \mathrm{H}$ \\
$\mathrm{C}_{2}$ & $\mathrm{H} / \mathrm{H} / \mathrm{VH}$ & $/$ & $\mathrm{H} / \mathrm{M} / \mathrm{L}$ & $\mathrm{FL} / \mathrm{M} / \mathrm{M}$ \\
$\mathrm{C}_{3}$ & $\mathrm{VH} / \mathrm{H} / \mathrm{H}$ & $\mathrm{FH} / \mathrm{M} / \mathrm{H}$ & $/$ & $\mathrm{M} / \mathrm{M} / \mathrm{FL}$ \\
$\mathrm{C}_{4}$ & $\mathrm{FH} / \mathrm{H} / \mathrm{H}$ & $\mathrm{H} / \mathrm{M} / \mathrm{H}$ & $\mathrm{M} / \mathrm{L} / \mathrm{M}$ & $/$ \\
\hline
\end{tabular}

Through the decision-maker's score, the subjective weights of the three experts are determined to be $0.5,0.3,0.2$, and $\alpha=0.5, \beta=0.5$. According to the method in the Section 5, the cloud direct-relation matrix $\tilde{X}$ of the main criterion after integrating the opinions of multiple experts is obtained. 


$$
\tilde{X}=\left[\begin{array}{cccc}
0 & (6.5252,0.3713,0.0579) & (6.2650,0.3852,0.0601) & (6.4730,0.3330,0.0520) \\
(6.5078,0.3590,0.0560) & 0 & (5.2209,0.2765,0.0432) & (4.7722,0.1507,0.0236) \\
(6.5600,0.3947,0.0616) & (5.7965,0.2289,0.0357) & 0 & (4.9089,0.1370,0.0215) \\
(6.3325,0.3062,0.0478) & (6.2520,0.3109,0.0486) & (4.7790,0.1742,0.0273) & 0
\end{array}\right]
$$

After normalization, the cloud total relation matrix $\tilde{T}=\left(T^{U}, T^{V}, T^{Y}\right)$ is obtained.

\begin{tabular}{lllllllllllll}
\hline$T^{U}$ & \multicolumn{1}{c}{$T^{V}$} \\
\hline 2.6537 & 2.8236 & 2.5714 & 2.5643 & 1.4358 & 1.5400 & 1.4760 & 1.4008 & 1.1510 & 1.2778 & 1.2446 & 0.9928 \\
2.6169 & 2.2930 & 2.2886 & 2.2623 & 1.5667 & 1.1855 & 1.3184 & 1.3126 & 1.1607 & 0.8120 & 0.9883 & 0.7316 \\
2.7009 & 2.6026 & 2.1485 & 2.3380 & 1.3817 & 1.1735 & 0.9504 & 1.0262 & 1.1653 & 0.9743 & 0.7746 & 0.7161 \\
2.7013 & 2.6240 & 2.3525 & 2.1420 & 1.3526 & 1.2441 & 1.1029 & 0.9323 & 1.1238 & 1.0338 & 0.9175 & 0.6033 \\
\hline
\end{tabular}

We can calculate the cloud threshold $\delta=(2.4802,1.2750,0.9792)$, and further obtain $\tilde{T}^{o}$.

$$
\tilde{T}^{o}=\left[\begin{array}{cccc}
(2.6537,1.4358,1.1510) & (2.8236,1.5400,1.2778) & (2.5714,1.4760,1.2446) & (2.5643,1.4008,0.9928) \\
(2.6169,1.5667,1.1607) & 0 & 0 & 0 \\
(2.7009,1.3817,1.1653) & (2.6026,1.1735,0.9743) & 0 & 0 \\
(2.7013,1.3526,1.1238) & (2.6240,1.2441,1.0338) & 0 & 0
\end{array}\right]
$$

The normalized relative cloud weight matrix $R^{\tilde{W}_{T}}$ is as follows.

$$
R^{\tilde{W}_{T}}=\left[\begin{array}{cccc}
(0.2467,0.2500,0.2453) & (0.2660,0.2631,0.2738) & (0.2423,0.2522,0.2667) & (0.2416,0.2393 .0 .2128) \\
(1,1,1) & 0 & 0 & 0 \\
(0.5093,0.5407,0.5446) & (0.4907,0.4593,0.4554) & 0 & 0 \\
(0.5073,0.5209,0.5209) & (0.4927,0.4791,0.4791) & 0 & 0
\end{array}\right]
$$

It can be seen from $\tilde{T}^{o}$ and $R^{\tilde{W}_{T}}$ that $\mathrm{C}_{1}$ has an inner dependencies. Through expert evaluation, the inner dependencies of $\mathrm{C}_{1}$ are shown in Tab.5.

Tab.5 Evaluation of inner dependencies on cost criteria $\mathrm{C}_{1}$

\begin{tabular}{llllllllll}
\hline & Expert 1 & \multicolumn{9}{c}{ Expert 1 } & \multicolumn{7}{c}{ Expert 3 } \\
\cline { 2 - 9 } & $c_{11}$ & $c_{12}$ & $c_{13}$ & $c_{11}$ & $c_{12}$ & $c_{13}$ & $c_{11}$ & $c_{12}$ & $c_{13}$ \\
\hline$c_{11}$ & & $\mathrm{M}$ & $\mathrm{H}$ & & $\mathrm{M}$ & $\mathrm{H}$ & & $\mathrm{FL}$ & $\mathrm{M}$ \\
$c_{12}$ & $\mathrm{M}$ & & $\mathrm{H}$ & $\mathrm{L}$ & & $\mathrm{M}$ & $\mathrm{L}$ & & $\mathrm{H}$ \\
$c_{13}$ & $\mathrm{M}$ & $\mathrm{FL}$ & & $\mathrm{FL}$ & $\mathrm{L}$ & & $\mathrm{L}$ & $\mathrm{M}$ & \\
\hline
\end{tabular}

Integrating the opinions of multiple experts to obtain the cloud direct-relation matrix of the sub-criteria under the $\operatorname{cost}$ is $\tilde{X}^{C}$

$$
\tilde{X}^{C}=\left[\begin{array}{ccc}
(0,0,0) & (4.9089,0.1370,0.0215) & (6.3257,0.3185,0.0497) \\
(3.8952,0.2953,0.0461) & (0,0,0) & (6.2520,0.3109,0.0486) \\
(4.2946,0.2231,0.0348) & (4.1298,0.2390,0.0373) & (0,0,0)
\end{array}\right]
$$

The normalized cloud total relation matrix of the sub-criterion under the is $R^{\tilde{W}^{C}}$.

$$
R^{\tilde{W}^{C}}=\left[\begin{array}{lll}
(0.2466,0.2859,0.2858) & (0.3341,0.2860,0.2863) & (0.4193,0.4281,0.4279) \\
(0.3126,0.3592,0.3590) & (0.2618,0.2331,0.2332) & (0.4256,0.4077,0.4078) \\
(0.3265,0.3587,0.3585) & (0.3402,0.3077,0.3079) & (0.3333,0.3336,0.3336)
\end{array}\right]
$$

\section{Stage 3: Using the ANP-cloud to calculate the cloud weight of each criterion}


The judgment matrices evaluated by each expert are shown in the Appendix. It should be pointed out that in any judgment matrix $\tilde{W}, \tilde{w}_{i i}=(1,0,0), \quad \tilde{w}_{i j}=1 / \tilde{w}_{i j}$. According to the method described in Section 5 , the unweighted cloud supermatrix is obtained as shown in Tab.6.

Tab.6 Unweighted cloud supermatrix

\begin{tabular}{|c|c|c|c|c|c|c|}
\hline & $c_{11}$ & $c_{12}$ & $c_{13}$ & $\ldots$ & $c_{44}$ & $c_{45}$ \\
\hline$c_{11}$ & $(0.2466,0.2859,0.2858)$ & $(0.3126,0.3592,0.3590)$ & $(0.3265,0.3587,0.3585)$ & $\ldots$ & $(0.2625,0.3374,0.3374)$ & $(0.6174,0.4051,0.4053)$ \\
\hline$c_{12}$ & $(0.3341,0.2860,0.2863)$ & $(0.2618,0.2330,0.2332)$ & $(0.3402,0.3077,0.3079)$ & $\cdots$ & $(0.1337,0.2699,0.2701)$ & $(0.2637,0.3446,0.3443)$ \\
\hline$c_{13}$ & $(0.4193,0.4281,0.4280)$ & $(0.4257,0.4078,0.4078)$ & $(0.3333,0.3335,0.3335)$ & ... & $(0.6038,0.3927,0.3925)$ & $(0.1189,0.2503,0.2504)$ \\
\hline$c_{21}$ & $(0.2000,0.3951,0.3955)$ & $(0.2529,0.3478,0.3480)$ & $(0.5593,0.3201,0.3201)$ & $\cdots$ & $(0.3357,0.3332,0.3332)$ & $(0.2500,0.3549,0.5550)$ \\
\hline$c_{22}$ & $(0.0877,0.1738,0.1745)$ & $(0.1005,0.2311,0.2310)$ & $(0.1511,0.3198,0.3198)$ & $\cdots$ & $(0.3333,0.3352,0.3353)$ & $(0.1232,0.2724,0.2725)$ \\
\hline$c_{23}$ & $(0.7123,0.4311,0.4300)$ & $(0.6466,0.4211,0.4210)$ & $(0.2895,0.3600,0.3600)$ & $\cdots$ & $(0.3310,0.3316,0.3315)$ & $(0.6268,0.3726,0.3725)$ \\
\hline$c_{31}$ & $(0.2633,0.2134,0.2133)$ & $(0.0685,0.1634,0.1634)$ & $(0.3871,0.2308,0.2308)$ & $\cdots$ & $(0,0,0)$ & $(0,0,0)$ \\
\hline$c_{32}$ & $(0.2881,0.2131,0.2131)$ & $(0.1723,0.1980,0.1980)$ & $(0.2522,0.2164,0.2163)$ & $\cdots$ & $(0,0,0)$ & $(0,0,0)$ \\
\hline$c_{33}$ & $(0.0743,0.1681,0.1681)$ & $(0.1054,0.1834,0.1833)$ & $(0.1698,0.2012,0.2012)$ & $\cdots$ & $(0,0,0)$ & $(0,0,0)$ \\
\hline$c_{34}$ & $(0.2636,0.2236,0.2236)$ & $(0.4036,0.2323,0.2323)$ & $(0.1154,0.1845,0.1846)$ & ... & $(0,0,0)$ & $(0,0,0)$ \\
\hline$c_{35}$ & $(0.1107,0.1818,0.1818)$ & $(0.2511,0.2230,0.2230)$ & $(0.0755,0.1670,0.1670)$ & $\ldots$ & $(0,0,0)$ & $(0,0,0)$ \\
\hline$c_{41}$ & $(0.1560,0.2068,0.2068)$ & $(0.1573,0.1969,0.1969)$ & $(0.1590,0.2056,0.2056)$ & ... & $(0,0,0)$ & $(0,0,0)$ \\
\hline$c_{42}$ & $(0.0996,0.1864,0.1864)$ & $(0.4093,0.2280,0.2280)$ & $(0.4029,0.2254,0.2254)$ & $\cdots$ & $(0,0,0)$ & $(0,0,0)$ \\
\hline$c_{43}$ & $(0.2487,0.2161,0.2610)$ & $(0.2543,0.2193,0.2194)$ & $(0.0982,0.1816,0.1816)$ & $\cdots$ & $(0,0,0)$ & $(0,0,0)$ \\
\hline$c_{44}$ & $(0.4290,0.2202,0.2201)$ & $(0.1058,0.1839,0.1839)$ & $(0.2527,0.2516,0.2516)$ & $\ldots$ & $(0,0,0)$ & $(0,0,0)$ \\
\hline$c_{45}$ & $(0.0666,0.1706,0.1706)$ & $(0.0733,0.1719,0.1719)$ & $(0.0692,0.1717,0.1718)$ & $\ldots$ & $(0,0,0)$ & $(0,0,0)$ \\
\hline
\end{tabular}

The supermatrix is weighted according to the relative cloud weight matrix $R^{\tilde{W}_{T}}$, and the weighted cloud supermatrix is shown in Tab.7.

Tab.7 Weighted cloud supermatrix

\begin{tabular}{|c|c|c|c|c|c|c|}
\hline & $c_{11}$ & $c_{12}$ & $c_{13}$ & $\ldots$ & $c_{44}$ & $c_{45}$ \\
\hline$c_{11}$ & $(0.0608,0.0937,0.0929)$ & $(0.0771,0.1182,0.1171)$ & $(0.0805,0.1204,0.1193)$ & $\cdots$ & $(0.1332,0.2191,0.2191)$ & $(0.3132,0.3187,0.3187)$ \\
\hline$c_{12}$ & $(0.0824,0.1093,0.1082)$ & $(0.0706,0.0918,0.0907)$ & $(0.0839,0.1140,0.1128)$ & $\ldots$ & $(0.0678,0.1536,0.1537)$ & $(0.1338,0.2223,0.2222)$ \\
\hline$c_{13}$ & $(0.1034,0.1488,0.1474)$ & $(0.1050,0.1464,0.1450)$ & $(0.0822,0.1174,0.1160)$ & $\cdots$ & $(0.3063,0.3723,0.3722)$ & $(0.0603,0.1413,0.1413)$ \\
\hline$c_{21}$ & $(0.0532,0.1175,0.1186)$ & $(0.0673,0.1140,0.1156)$ & $(0.1488,0.1700,0.1752)$ & $\cdots$ & $(0.1654,0.2298,0.2298)$ & $(0.1232,0.2119,0.2120)$ \\
\hline$c_{22}$ & $(0.0233,0.0517,0.0523)$ & $(0.0267,0.0669,0.0673)$ & $(0.0402,0.0939,0.0946)$ & $\cdots$ & $(0.1642,0.2297,0.2298)$ & $(0.0607,0.1466,0.1467)$ \\
\hline$c_{23}$ & $(0.1895,0.2197,0.2261)$ & $(0.1720,0.2037,0.2095)$ & $(0.0770,0.1224,0.1243)$ & $\cdots$ & $(0.1631,0.2277,0.2277)$ & $(0.3088,0.3520,0.3519)$ \\
\hline$c_{31}$ & $(0.0638,0.0842,0.0872)$ & $(0.0166,0.0432,0.0436)$ & $(0.0938,0.1125,0.1174)$ & $\ldots$ & $(0,0,0)$ & $(0,0,0)$ \\
\hline$c_{32}$ & $(0.0698,0.0891,0.0926)$ & $(0.0417,0.0647,0.0664)$ & $(0.0611,0.0824,0.0853)$ & $\cdots$ & $(0,0,0)$ & $(0,0,0)$ \\
\hline$c_{33}$ & $(0.0180,0.0448,0.0453)$ & $(0.0255,0.0518,0.0526)$ & $(0.0411,0.0649,0.0665)$ & $\cdots$ & $(0,0,0)$ & $(0,0,0)$ \\
\hline$c_{34}$ & $(0.0639,0.0858,0.0888)$ & $(0.0975,0.1161,0.1212)$ & $(0.0280,0.0533,0.0543)$ & $\cdots$ & $(0,0,0)$ & $(0,0,0)$ \\
\hline$c_{35}$ & $(0.0268,0.0522,0.0530)$ & $(0.0608,0.0832,0.0860)$ & $(0.0183,0.0447,0.0452)$ & $\cdots$ & $(0,0,0)$ & $(0,0,0)$ \\
\hline$c_{41}$ & $(0.0377,0.0624,0.0600)$ & $(0.0380,0.0607,0.0582)$ & $(0.0384,0.0626,0.0601)$ & $\cdots$ & $(0,0,0)$ & $(0,0,0)$ \\
\hline$c_{42}$ & $(0.0241,0.0510,0.0498)$ & $(0.0989,0.1124,0.1034)$ & $(0.1017,0.1145,0.1048)$ & $\ldots$ & $(0,0,0)$ & $(0,0,0)$ \\
\hline$c_{43}$ & $(0.0601,0.0792,0.0743)$ & $(0.0614,0.0807,0.0758)$ & $(0.0237,0.0498,0.0486)$ & $\cdots$ & $(0,0,0)$ & $(0,0,0)$ \\
\hline$c_{44}$ & $(0.1036,0.1156,0.1056)$ & $(0.0256,0.0511,0.0498)$ & $(0.0611,0.0798,0.0749)$ & $\ldots$ & $(0,0,0)$ & $(0,0,0)$ \\
\hline$c_{45}$ & $(0.0161,0.0442,0.0436)$ & $(0.0177,0.0451,0.0444)$ & $(0.0167,0.0447,0.0440)$ & $\ldots$ & $(0,0,0)$ & $(0,0,0)$ \\
\hline
\end{tabular}

According to the method in the Section 5, the cloud limiting supermatrix is obtained. Finally, the cloud weight of each criterion is obtained as shown in Tab.8. 
Tab.8 The cloud weight of each criterion

\begin{tabular}{ccc}
\hline Main criteria & Sub-criteria & Cloud weight \\
\hline & $c_{11}$ & $(0.1713,0.1724,0.1730)$ \\
$\mathbf{C}_{\mathbf{1}}$ & $c_{12}$ & $(0.1218,0.1347,0.1346)$ \\
& $c_{13}$ & $(0.2094,0.1948,0.1946)$ \\
& & \\
& $c_{21}$ & $(0.0799,0.0829,0.0835)$ \\
$\mathbf{C}_{2}$ & $c_{22}$ & $(0.0415,0.0562,0.0560)$ \\
& $c_{23}$ & $(0.1324,0.1133,0.1147)$ \\
& $c_{31}$ & $(0.0327,0.0292,0.0303)$ \\
$\mathbf{C}_{3}$ & $c_{32}$ & $(0.0299,0.0277,0.0288)$ \\
& $c_{33}$ & $(0.0148,0.0189,0.0193)$ \\
& $c_{34}$ & $(0.0287,0.0282,0.0292)$ \\
& $c_{35}$ & $(0.0158,0.0200,0.0204)$ \\
$\mathbf{C}_{4}$ & $c_{41}$ & $(0.0192,0.0215,0.0207)$ \\
& $c_{42}$ & $(0.0375,0.0319,0.0297)$ \\
& $c_{43}$ & $(0.0228,0.0236,0.0225)$ \\
& $c_{44}$ & $(0.0338,0.0293,0.0274)$ \\
\hline
\end{tabular}

\section{Stage 4: The best maintenance strategy for the rotating body rotation MU of CNC machine tool}

Tab.9 shows the scores of three experts on various criteria of different maintenance strategies of the rotating body rotation MU.

Tab.9 Scores of different maintenance strategy criteria for the rotating body rotation MU

\begin{tabular}{|c|c|c|c|c|c|c|c|c|c|c|c|c|c|}
\hline \multirow{3}{*}{$\begin{array}{l}\text { Main } \\
\text { criteria }\end{array}$} & \multirow{3}{*}{ Sub-criteria } & \multicolumn{3}{|l|}{$\mathrm{CM}$} & \multicolumn{3}{|l|}{ TBM } & \multicolumn{3}{|l|}{ CBM } & \multicolumn{3}{|l|}{ PdM } \\
\hline & & Expert & Expert & Expert & Expert & Expert & Expert & Expert & Expert & Expert & Expert & Expert & Expert \\
\hline & & 1 & 2 & 3 & 1 & 2 & 3 & 1 & 2 & 3 & 1 & 2 & 3 \\
\hline \multirow{3}{*}{$\mathrm{C}_{1}$} & $c_{11}$ & $\mathrm{H}$ & $\mathrm{H}$ & VH & $\mathrm{FH}$ & FH & $\mathrm{H}$ & M & M & FH & M & M & $\mathrm{FH}$ \\
\hline & $c_{12}$ & $\mathrm{H}$ & $\mathrm{EH}$ & VH & $\mathrm{H}$ & VH & $\mathrm{H}$ & FH & $\mathrm{F}$ & FH & FH & $\mathrm{M}$ & FH \\
\hline & $c_{13}$ & EH & VH & EH & VH & VH & VH & $\mathrm{H}$ & $\mathrm{H}$ & $\mathrm{H}$ & FH & $\mathrm{H}$ & $\mathrm{FH}$ \\
\hline \multirow{3}{*}{$\mathrm{C}_{2}$} & $c_{21}$ & M & M & M & FH & $\mathrm{H}$ & FH & $\mathrm{H}$ & VH & VH & $\mathrm{H}$ & VH & VH \\
\hline & $c_{22}$ & FH & M & M & $\mathrm{FH}$ & $\mathrm{FH}$ & FH & $\mathrm{H}$ & VH & $\mathrm{H}$ & $\mathrm{H}$ & VH & $\mathrm{H}$ \\
\hline & $c_{23}$ & $\mathrm{FL}$ & VL & $\mathrm{L}$ & M & FH & FH & VH & $\mathrm{H}$ & VH & VH & VH & VH \\
\hline \multirow{5}{*}{$\mathrm{C}_{3}$} & $c_{31}$ & M & FH & FH & $\mathrm{FH}$ & FH & $\mathrm{H}$ & $\mathrm{H}$ & $\mathrm{H}$ & VH & EH & EH & VH \\
\hline & $c_{32}$ & M & VL & VL & FH & FL & $\mathrm{FL}$ & $\mathrm{H}$ & $\mathrm{H}$ & $\mathrm{H}$ & VH & EH & VH \\
\hline & $c_{33}$ & $\mathrm{FL}$ & M & $\mathrm{VL}$ & $\mathrm{FH}$ & M & FL & $\mathrm{H}$ & $\mathrm{H}$ & $\mathrm{H}$ & $\mathrm{H}$ & VH & VH \\
\hline & $c_{34}$ & $\mathrm{~L}$ & $\mathrm{~L}$ & M & M & $\mathrm{FL}$ & M & VH & $\mathrm{FH}$ & $\mathrm{H}$ & VH & $\mathrm{H}$ & $\mathrm{H}$ \\
\hline & $c_{35}$ & VH & $\mathrm{H}$ & VH & VL & VL & $\mathrm{L}$ & FH & $\mathrm{H}$ & M & FH & $\mathrm{H}$ & M \\
\hline \multirow{5}{*}{$\mathrm{C}_{4}$} & $c_{41}$ & VH & EH & VH & $\mathrm{H}$ & VH & $\mathrm{H}$ & $\mathrm{L}$ & M & VL & $\mathrm{VL}$ & $\mathrm{FL}$ & VL \\
\hline & $c_{42}$ & $\mathrm{FL}$ & FH & $\mathrm{H}$ & FL & FH & $\mathrm{H}$ & $\mathrm{FH}$ & $\mathrm{H}$ & VH & $\mathrm{H}$ & $\mathrm{H}$ & VH \\
\hline & $c_{43}$ & $\mathrm{VH}$ & VH & $\mathrm{H}$ & FH & $\mathrm{H}$ & $\mathrm{H}$ & $\mathrm{L}$ & $\mathrm{FL}$ & M & $\mathrm{VL}$ & $\mathrm{FL}$ & $\mathrm{FL}$ \\
\hline & $c_{44}$ & EH & EH & VH & VH & $\mathrm{H}$ & $\mathrm{H}$ & M & M & FH & $\mathrm{L}$ & $\mathrm{FL}$ & $\mathrm{FH}$ \\
\hline & $c_{45}$ & EH & EH & $\mathrm{VH}$ & $\mathrm{FH}$ & $\mathrm{H}$ & $\mathrm{FH}$ & $\mathrm{M}$ & $\mathrm{M}$ & $\mathrm{M}$ & $\mathrm{M}$ & $\mathrm{FL}$ & $\mathrm{L}$ \\
\hline
\end{tabular}

According to the scores of each criterion of different maintenance strategies for the rotating body rotation MU and the cloud weight corresponding to each criterion, the comprehensive scores of each maintenance strategy are $\tilde{S}_{\text {total }}^{A_{1}}=(5.9257,2.2188,2.1821) \quad \tilde{S}_{\text {total }}^{A_{2}}=(6.0673,2.1879,2.1388) \quad, \quad \tilde{S}_{\text {total }}^{A_{3}}=(6.0710,2.1275,2.0658)$ 
$\tilde{S}_{\text {total }}^{A_{4}}=(5.9301,2.0618,2.0054)$, respectively. Therefore, the priority of maintenance strategy of the rotating body rotation MU of CNC machine tools is $C B M>T B M>P \mathrm{dM}>\mathrm{CM}$, and its optimal maintenance strategy is CBM.

6.3 comparative analysis

In order to verify the effectiveness and superiority of the method proposed in this paper, the traditional DEMATE-ANP(Büyüközkan and Güleryüz 2016), fuzzy DEMATE-ANP(Kiani Mavi and Standing 2018)are also used to sort the maintenance strategies of the above-mentioned rotating body rotation MU. The comparison results are shown in Tab.10.

Tab.10 Ranking results of maintenance strategy for the rotating body rotation MU by different methods

\begin{tabular}{cccccc}
\hline \multirow{2}{*}{$\begin{array}{c}\text { Maintenance } \\
\text { strategies }\end{array}$} & \multicolumn{2}{c}{ Traditional DEMATE-ANP } & \multicolumn{2}{c}{ Fuzzy DEMATEL-ANP } & \multicolumn{2}{c}{ The proposed method } \\
\hline$C M$ & 6.5394 & 1 & $(6.5198,6.5376,7.5469)$ & 2 & 4 \\
Comprehensive score & Ranking & Fuzzy comprehensive score & Ranking & $(5.9258,2.2188,2.1821)$ \\
$T B M$ & 6.5245 & 2 & $(5.5357,6.5406,7.5438)$ & 1 & $(6.0673,2.1879,2.1388)$ \\
$C B M$ & 6.4739 & 3 & $(5.4731,6.4789,7.4825)$ & 3 & $(6.0710,2.1275,2.0658)$ \\
$P d M$ & 6.3326 & 4 & $(5.3118,6.3211,7.3264)$ & 4 & $(5.9301,2.0618,2.0054)$ \\
\hline
\end{tabular}

As shown in Table 10, for the maintenance strategy ranking results of the rotating body rotation MU of the CNC turntable, the priority of the maintenance strategy calculated by the method proposed in this paper is $C B M>T B M>P \mathrm{dM}>\mathrm{CM}$, and the optimal maintenance strategy is the CBM; the priority of maintenance strategy based on the traditional DEMATEL-ANP method is $C M>T B M>C B M>P \mathrm{dM}$, and the optimal maintenance strategy is CM; the priority order of maintenance strategy based on fuzzy DEMATEL-ANP is $T B M>C M>C B M>P \mathrm{dM}$, and the optimal maintenance strategy is TBM. From the overall ranking results, compared with the traditional DEMATEL-ANP method, the proposed method has different rankings except that the TBM is ranked second. The inconsistent results may mainly come from the following aspects: 1) the traditional DEMATEL-ANP ignores the randomness and fuzziness of expert evaluation, and uses $1 \sim 9$ scale accurate numbers to describe the expert evaluation of each criterion, which may lead to the loss of information. 2) Traditional DEMATEL-ANP synthesizes the opinions of multiple experts by taking the mean value, without considering the subjective weight and objective weight of experts' opinions, and the comprehensive result may be unscientific. Compared with the ranking results obtained by fuzzy DEMATEL-ANP, the ranking results of each maintenance strategy are different. Although the fuzzy DEMATEL-ANP considers the fuzziness in the evaluation process, it still lacks the consideration of randomness and subjective and objective evaluation weight, and obtains the unscientific ranking results of maintenance strategies. From the perspective of the optimal maintenance strategy of the rotating body rotation $\mathrm{MU}$ of the $\mathrm{CNC}$ turntable, the $\mathrm{CM}$ is obviously unreasonable. The rotating body rotation MU is a very important $\mathrm{MU}$ in the $\mathrm{CNC}$ machine tool. The $\mathrm{CM}$ is easy to lead to frequent faults and downtime loss. The reason for adopting $\mathrm{CBM}$ for the rotating body rotation $\mathrm{MU}$ of the $\mathrm{CNC}$ turntable may be that $\mathrm{CBM}$ is less prone to failure than TBM, resulting in equipment damage, casualties, etc.

\section{Conclusion}

In this paper, a multi-criteria group decision-making method based on cloud DEMATEL-ANP is proposed to calculate the cloud weight of decision-making criteria of the maintenance strategy selection. The subjective and objective weighting method is used to aggregate the evaluation of experts. Finally, the comprehensive score cloud values of different maintenance strategies are obtained. The effectiveness of the proposed method is verified through the ranking of 
maintenance strategies of the rotating body rotation MU of the CNC turntable and the comparative analysis of different methods. The method proposed in this paper considers the dependencies between evaluation criteria and the randomness and fuzziness of the experts' evaluation, which can reduce information loss, make the ranking results of maintenance strategy more accurate and reliable, and better guide enterprises to carry out maintenance work, improve the reliability and safety of equipment and reduce production loss. However, this paper only studies the maintenance strategy of a single MU without considering the interaction between units. The synthesis of maintenance strategy of multiple MUs is worthy of further research. At the same time, how to improve the efficiency of the method is also worth considering.

\section{Acknowledgements}

This work is financially supported by the National Natural Science Foundation of China (No. 51835001), the Independent Research Project of State Key Laboratory of Mechanical Transmission, China (SKLMT-ZZKT-2021R06).

\section{References}

Aghaee, M., \& Fazli, S. (2012). An improved MCDM method for maintenance approach selection: A case study of auto industry. Management Science Letters, 2, 137-146. https://doi.org/10.5267/j.msl.2011.09.012

Animah, I., \& Shafiee, M. (2021). Maintenance strategy selection for critical shipboard machinery systems using a hybrid AHP-PROMETHEE and cost benefit analysis: a case study. Journal of Marine Engineering and Technology, 20(5), 312-323. https://doi.org/10.1080/20464177.2019.1572705

Arjomandi, M. A., Dinmohammadi, F., Mosallanezhad, B., \& Shafiee, M. (2021). A fuzzy DEMATEL-ANP-VIKOR analytical model for maintenance strategy selection of safety critical assets. Advances in Mechanical Engineering, 13(4), 1-21. https://doi.org/10.1177/1687814021994965

Ashraf W.Labib. (1998). World-class maintenance using a computerised maintenance management system. Journal of Quality in Maintenance Engineering, 4(1), 66-75.

Azid, I. A. (2014). Development of a model for optimal maintenance policy selection Siew-Hong Ding , Shahrul Kamaruddin * and, 8(1), 50-68.

Bevilacqua, M., \& Braglia, M. (2000). Analytic hierarchy process applied to maintenance strategy selection. Reliability Engineering and System Safety, 70(1), 71-83. https://doi.org/10.1016/S0951-8320(00)00047-8

Bevilacqua, Maurizio, Braglia, M., \& Gabbrielli, R. (2000). Monte Carlo simulation approach for a modified FMECA in a power plant. Quality and Reliability Engineering International, 16(4), 313-324. https://doi.org/10.1002/1099-1638(200007/08)16:4<313::AID-QRE434>3.0.CO;2-U

Bian, T., Zheng, H., \& Yin, L. (2018). Failure mode and effects analysis based on D numbers and TOPSIS. Quality and Reliability Engineering International, 34, 501-515. https://doi.org/10.1002/qre.2268

Büyüközkan, G., \& Güleryüz, S. (2016). An integrated DEMATEL-ANP approach for renewable energy resources selection in Turkey. International Journal of Production Economics, 182, 435-448. https://doi.org/10.1016/j.ijpe.2016.09.015

Carpitella, S., Mzougui, I., Benítez, J., Carpitella, F., \& Certa, A. (2020). A risk evaluation framework for the best maintenance strategy: The case of a marine salt manufacture firm. Reliability Engineering and System Safety.

Chan, F. T. S., \& Prakash, A. (2012). Maintenance policy selection in manufacturing firms using the fuzzy MCDM approach. International Journal of Production Research, 50(23), 7044-7056. https://doi.org/10.1080/00207543.2011.653451

Dey, P. K. (2004). Decision support system for inspection and maintenance: A case study of oil pipelines. IEEE Transactions on Engineering Management, 51(1), 47-56. https://doi.org/10.1109/TEM.2003.822464 
Ding, S. H., Goh, T. T., Tan, P. S., Wee, S. C., \& Kamaruddin, S. (2012). Implementation of decision tree for maintenance policy decision making- A case study in semiconductor industry. Advanced Materials Research, 591593, 704-707. https://doi.org/10.4028/www.scientific.net/AMR.591-593.704

Ding, S. H., \& Kamaruddin, S. (2015). Maintenance policy optimization-literature review and directions. International Journal of Advanced Manufacturing Technology, 76(5-8), 1263-1283. https://doi.org/10.1007/s00170-014-6341-2

Ding, S. H., Kamaruddin, S., \& Azid, I. A. (2014). Maintenance policy selection model - A case study in the palm oil industry. Journal of Manufacturing Technology Management, 25(3), 415-435. https://doi.org/10.1108/JMTM-03-2012-0032

Emovon, I., Norman, R. A., \& Murphy, A. J. (2018). Hybrid MCDM based methodology for selecting the optimum maintenance strategy for ship machinery systems. Journal of Intelligent Manufacturing, 29(3), 519-531. https://doi.org/10.1007/s10845-015-1133-6

Fernandez, O., Labib, A., Walmsley, R., \& Petty, D. (2003). A decision support maintenance management system. International Journal of Quality \& Reliability Management, 20(8), 965-979.

Gao, H., Ju, Y., Gonzalez, E. D. R. S., Zeng, X. J., Dong, P., \& Wang, A. (2021). Identifying critical causal criteria of green supplier evaluation using heterogeneous judgements: An integrated approach based on cloud model and DEMATEL. Applied Soft Computing, 113. https://doi.org/10.1016/j.asoc.2021.107882

Ge, Y., Xiao, M., Yang, Z., Zhang, L., Hu, Z., \& Feng, D. (2017). An integrated logarithmic fuzzy preference programming based methodology for optimum maintenance strategies selection. Applied Soft Computing Journal, 60, 591-601. https://doi.org/10.1016/j.asoc.2017.07.021

Gölcük, I., \& Baykasołlu, A. (2016). An analysis of DEMATEL approaches for criteria interaction handling within ANP. Expert Systems with Applications, 46, 346-366. https://doi.org/10.1016/j.eswa.2015.10.041

Goossens, A. J. M., \& Basten, R. J. I. (2015). Exploring maintenance policy selection using the Analytic Hierarchy Process; An application for naval ships. Reliability Engineering and System Safety, 142, 31-41. https://doi.org/10.1016/j.ress.2015.04.014

Grinstead C.M., \& Snell J.L. (2006). Introduction To Probability. Rhode Island: American Mathematical Society.

Gupta, S., Maiti, J., Kumar, R., \& Kumar, U. (2009). A control chart guided maintenance policy selection. International Journal of Mining, Reclamation and Environment, 23(3), 216-226. https://doi.org/10.1080/17480930902916478

Hemmati, N., Rahiminezhad Galankashi, M., Imani, D. M., \& Farughi, H. (2018). Maintenance policy selection: a fuzzy-ANP approach. Journal of Manufacturing Technology Management, 29(7), $1253-1268$. https://doi.org/10.1108/JMTM-06-2017-0109

Ighravwe, D. E., \& Oke, S. A. (2019). A multi-criteria decision-making framework for selecting a suitable maintenance strategy for public buildings using sustainability criteria. Journal of Building Engineering, 24(September 2018), 100753. https://doi.org/10.1016/j.jobe.2019.100753

Jamali, N., Feylizadeh, M. R., \& Liu, P. (2021). Prioritization of aircraft maintenance unit strategies using fuzzy Analytic Network Process: A case study. Journal of Air Transport Management, 93(February), 102057. https://doi.org/10.1016/j.jairtraman.2021.102057

Jia, X., \& Xu, J. (2014). Cloud model-based seismic risk assessment of road in earthquake region. Journal of Tongji University(natural science), 42(9), 1352-1358.

Kiani Mavi, R., \& Standing, C. (2018). Critical success factors of sustainable project management in construction: A fuzzy DEMATEL-ANP approach. Journal of Cleaner Production, 194, 751-765. https://doi.org/10.1016/j.jclepro.2018.05.120

Kirubakaran, B., \& Ilangkumaran, M. (2016). Selection of optimum maintenance strategy based on FAHP integrated with GRA-TOPSIS. Annals of Operations Research, 245(1-2), $285-313$. https://doi.org/10.1007/s10479-014-1775-3 
Lazakis, I., \& Ölçer, A. (2016). Selection of the best maintenance approach in the maritime industry under fuzzy multiple attributive group decision-making environment. Proceedings of the Institution of Mechanical Engineers Part M: Journal of Engineering for the Maritime Environment, 230(2), 297-309. https://doi.org/10.1177/1475090215569819

Li, C., Qi, Z., \& Feng, X. (2014). A multi-risks group evaluation method for the informatization project under linguistic environment. Journal of Intelligent \& Fuzzy Systems, 26(3), 1581-1592.

Li, Dacheng, \& Gao, J. (2010). Study and application of Reliability-centered Maintenance considering Radical Maintenance. Journal of Loss Prevention in the Process Industries, 23(5), 622-629. https://doi.org/10.1016/j.jlp.2010.06.008

Li, Deyi, \& Liu, C. (2004). Study on the universality of the normal cloud model. Engineering Science, 6(8), 28-34.

Li, Deyi, Liu, C., \& Gan, W. (2009). A New Cognitive Model: Cloud Model. International Journal of Intelligent Systems, 24, 357-375.

Li, X., Ran, Y., Wan, F., Yu, H., Zhang, G., \& He, Y. (2021). Condition-based maintenance strategy optimization of meta-action unit considering imperfect preventive maintenance based on Wiener process. Flexible Services and Manufacturing Journal. https://doi.org/10.1007/s10696-021-09407-w

Li, X., Ran, Y., Yu, H., Chen, Y., \& Zhang, G. (2021). Maintenance decision of meta-action unit based on Grey-BWM. In IOP Conference Series: Materials Science and Engineering (Vol. 1043, p. 032032). Xian. https://doi.org/10.1088/1757-899x/1043/3/032032

Li, X., Ran, Y., \& Zhang, G. (2021). Optimization of equal-cycle maintenance strategy considering imperfect preventive maintenance. Proceedings of the Institution of Mechanical Engineers, Part E: Journal of Process Mechanical Engineering. https://doi.org/https://doi.org/10.1177/09544089211063852

Li, X., Ran, Y., Zhang, G., \& He, Y. (2020). A failure mode and risk assessment method based on cloud model. Journal of Intelligent Manufacturing, 31(6), 1339-1352. https://doi.org/10.1007/s10845-019-01513-9

Li, Y., Wu, C., Zhang, X., Ran, Y., \& Zhang, G. (2021). Early failure mechanism research of electromechanical product based on meta-action. Engineering Failure Analysis, 122(January), 105217. https://doi.org/10.1016/j.engfailanal.2021.105217

Liou, J. J. H., Tzeng, G. H., \& Chang, H. C. (2007). Airline safety measurement using a hybrid model. Journal of Air Transport Management, 13(4), 243-249. https://doi.org/10.1016/j.jairtraman.2007.04.008

Liu, H.-C., You, J.-X., Fan, X.-J., \& Lin, Q.-L. (2014). Failure mode and effects analysis using D numbers and grey relational projection method. Expert Systems with Applications, 41(10), 4670-4679. https://doi.org/https://doi.org/10.1016/j.eswa.2014.01.031

Liu, H., Wang, L., Li, Z., \& Hu, Y. (2019). Improving Risk Evaluation in FMEA With Cloud Model and Hierarchical TOPSIS Method. IEEE Transactions on Fuzzy Systems, 27(1), 84-95. https://doi.org/10.1109/TFUZZ.2018.2861719

Mengsheng, Y. (2018). Research on reliability analysis technology of typical meta-action units of NC machine tools. Chongqing University.

Montero Jiménez, J. J., Vingerhoeds, R., Grabot, B., \& Schwartz, S. (2021). An Ontology Model for Maintenance Strategy Selection and Assessment. Under review. Journal of Intelligent Manufacturing. under review. https://doi.org/10.1007/s10845-021-01855-3

Mu, Z., Ran, Y., Zhang, G., Wang, H., \& Yang, X. (2021). Remaining useful life prediction method for machine tools based on meta-action theory. Proceedings of the Institution of Mechanical Engineers, Part O: Journal of Risk and Reliability, 235(4), 580-590. https://doi.org/10.1177/1748006X211002544

Özcan, E. C., Ünlüsoy, S., \& Eren, T. (2017). A combined goal programming - AHP approach supported with TOPSIS for maintenance strategy selection in hydroelectric power plants. Renewable and Sustainable Energy Reviews, 
78(June), 1410-1423. https://doi.org/10.1016/j.rser.2017.04.039

Rosqvist, T., Laakso, K., \& Reunanen, M. (2009). Value-driven maintenance planning for a production plant. Reliability Engineering and System Safety, 94(1), 97-110. https://doi.org/10.1016/j.ress.2007.03.018

Sadeghi, A., \& Manesh, R. A. (2012). The Application of Fuzzy Group Analytic Network Process to Selection of Best Maintenance Strategy- A Case Study in Mobarakeh Steel Company, Iran. Procedia - Social and Behavioral Sciences, 62(Mcdm), 1378-1383. https://doi.org/10.1016/j.sbspro.2012.09.236

Shi, H., Liu, H., Li, P., \& Xu, X. (2017). An integrated decision making approach for assessing healthcare waste treatment technologies from a multiple stakeholder. Waste Management, 59, 508-517. https://doi.org/10.1016/j.wasman.2016.11.016

Shyjith, K., Ilangkumaran, M., \& Kumanan, S. (2008). Multi-criteria decision-making approach to evaluate optimum maintenance strategy in textile industry. Journal of Quality in Maintenance Engineering, 14(4), 375-386. https://doi.org/10.1108/13552510810909975

Tan, Z., Li, J., Wu, Z., Zheng, J., \& He, W. (2011). An evaluation of maintenance strategy using risk based inspection. Safety Science, 49(6), 852-860. https://doi.org/10.1016/j.ssci.2011.01.015

Tersine RJ. (1985). Production/operations management: concepts, structure, and analysis. New York: Elsevier Science Publisher.

Tiejun, C., \& Yundong, M. (2016). Study on importance of factor of roadway roof fall based on ANP-ECM. Appliction research of computers, 33(11), 3307-3310.

Waeyenbergh, G., \& Pintelon, L. (2002). A framework for maintenance concept development. International Journal of Production Economics, 77(3), 299-313. https://doi.org/10.1016/S0925-5273(01)00156-6

Waeyenbergh, G., \& Pintelon, L. (2004). Maintenance concept development: A case study. International Journal of Production Economics, 89(3), 395-405. https://doi.org/10.1016/j.ijpe.2003.09.008

Wang Lihong. (2013). Quantitative simulation method fusing qualitative information based on cloud model. Computer simulation, 30(4), 348-352.

Wang Yang. (2018). Research on key techniques of reliability modeling and analysis for CNC machine tools. Chongqing University.

Yan, R., Fleury, M., Merler, M., Natsev, A., Smith, J. R., \& Watson, I. B. M. T. J. (2009). Large-Scale Multimedia Semantic Concept Modeling using Robust Subspace Bagging and MapReduce. In Proceeding LS-MMRM'09 Proceedings of the First ACM Workshop on Large-scale Multimedia Retrieval and Mining (pp. 35-42). New York.

Yang, X., Yan, L., \& Zeng, L. (2013). How to handle uncertainties in AHP: The Cloud Delphi hierarchical analysis. Information Sciences, 222, 384-404. https://doi.org/10.1016/j.ins.2012.08.019

Yu, H., Zhang, G., \& Ran, Y. (2019). A More Reasonable Definition of Failure Mode for Mechanical Systems Using Meta-Action. IEEE Access, 7, 4898-4904. https://doi.org/10.1109/ACCESS.2018.2888542

Yu, H., Zhang, G., Ran, Y., Li, M., Jiang, D., \& Chen, Y. (2019). A Reliability Allocation Method for Mechanical Product Based on Meta-Action. IEEE Transactions on Reliability, 1-9. https://doi.org/10.1109/TR.2019.2907517 


\section{Appendix}

Tab.A1 Experts' pairwise comparison matrix of sub-criteria in safety about hardware

\begin{tabular}{|c|c|c|c|c|c|c|c|c|c|c|}
\hline \multirow{2}{*}{$c_{11}$} & \multicolumn{3}{|c|}{ Expert 1} & \multicolumn{3}{|c|}{ Expert 2} & \multicolumn{3}{|c|}{ Expert 3} & \multirow{2}{*}{ Cloud weight } \\
\hline & $c_{21}$ & $c_{22}$ & $c_{23}$ & $c_{21}$ & $c_{22}$ & $c_{23}$ & $c_{21}$ & $c_{22}$ & $c_{23}$ & \\
\hline$c_{21}$ & & & M & & & MI & & & M & {$[0.2000,0.3951,0.3955]$} \\
\hline$c_{22}$ & QI & & SI & SI & & SI & I & & I & {$[0.7123,0.4311,0.4300]$} \\
\hline$c_{23}$ & & & & & & & & & & {$[0.0877,0.1738,0.1745]$} \\
\hline
\end{tabular}

Tab.A2 Experts' pairwise comparison matrix of sub-criteria in safety about software

\begin{tabular}{|c|c|c|c|c|c|c|c|c|c|c|}
\hline \multirow{2}{*}{$c_{12}$} & \multicolumn{3}{|c|}{ Expert 1} & \multicolumn{3}{|c|}{ Expert 2} & \multicolumn{3}{|c|}{ Expert 3} & \multirow{2}{*}{ Cloud weight } \\
\hline & $c_{21}$ & $c_{22}$ & $c_{23}$ & $c_{21}$ & $c_{22}$ & $c_{23}$ & $c_{21}$ & $c_{22}$ & $c_{23}$ & \\
\hline$c_{21}$ & & & M & & & MI & & & M & {$[0.2529,0.3478,0.3480]$} \\
\hline$c_{22}$ & M & & QI & SI & & QI & I & & SI & {$[0.6466,0.4211,0.4210]$} \\
\hline$c_{23}$ & & & & & & & & & & {$[0.1005,0.2311,0.2310]$} \\
\hline
\end{tabular}

Tab.A3 Experts' pairwise comparison matrix of sub-criteria in safety about personnel training

\begin{tabular}{lcccccccccc}
\hline & \multicolumn{3}{c}{ Expert 1 } & \multicolumn{5}{c}{ Expert 2 } & \multicolumn{3}{c}{ Expert 3 } & Cloud weight \\
\cline { 2 - 8 } & $c_{21}$ & $c_{22}$ & $c_{23}$ & $c_{21}$ & $c_{22}$ & $c_{23}$ & $c_{21}$ & $c_{22}$ & $c_{23}$ & \\
\hline$c_{21}$ & & VI & SI & & SI & SI & & SI & VI & {$[0.7406,0.3308,0.3305]$} \\
$c_{22}$ & & & & & & & & & {$[0.0892,0.2987,0.0989]$} \\
$c_{23}$ & & & & & & & & & & \\
\hline
\end{tabular}

Tab.A4 Experts' pairwise comparison matrix of sub-criteria in safety about product quality

\begin{tabular}{ccccccccccc}
\hline & \multicolumn{3}{c}{ Expert 1 } & \multicolumn{5}{c}{ Expert 2 } & \multicolumn{3}{c}{ Expert 3 } & Cloud weight \\
\cline { 2 - 8 } & $c_{21}$ & $c_{22}$ & $c_{23}$ & $c_{21}$ & $c_{22}$ & $c_{23}$ & $c_{21}$ & $c_{22}$ & $c_{23}$ & \\
\hline$c_{21}$ & & & $\mathrm{I}$ & & & $\mathrm{M}$ & & & $\mathrm{I}$ & {$[0.2377,0.3373,0.3371]$} \\
$c_{22}$ & $\mathrm{I}$ & & $\mathrm{SI}$ & $\mathrm{I}$ & & $\mathrm{SI}$ & $\mathrm{M}$ & & $\mathrm{I}$ & {$[0.6779,0.4382,0.4383]$} \\
$c_{23}$ & & & & & & & & & & {$[0.0844,0.2245,0.2246]$} \\
\hline
\end{tabular}

Tab.A5 Experts' pairwise comparison matrix of sub-criteria in safety about spare parts requirements

\begin{tabular}{|c|c|c|c|c|c|c|c|c|c|c|}
\hline \multirow{2}{*}{$c_{32}$} & \multicolumn{3}{|c|}{ Expert 1} & \multicolumn{3}{|c|}{ Expert 2} & \multicolumn{3}{|c|}{ Expert 3} & \multirow{2}{*}{ Cloud weight } \\
\hline & $c_{21}$ & $c_{22}$ & $c_{23}$ & $c_{21}$ & $c_{22}$ & $c_{23}$ & $c_{21}$ & $c_{22}$ & $c_{23}$ & \\
\hline$c_{21}$ & & M & & & I & & & MI & & {$[0.3126,0.3488,0.3488]$} \\
\hline$c_{22}$ & & & VI & & & SI & & & QI & {$[0.2950,0.2798,0.2794]$} \\
\hline$c_{23}$ & I & & & QI & & & MI & & & {$[0.2950,0.2798,0.2794]$} \\
\hline
\end{tabular}


Tab.A6 Experts' pairwise comparison matrix of sub-criteria in safety about production loss

\begin{tabular}{ccccccccccc}
\hline & \multicolumn{3}{c}{ Expert 1 } & \multicolumn{3}{c}{ Expert 2 } & \multicolumn{3}{c}{ Expert 3 } & Cloud weight \\
\cline { 2 - 9 }$c_{33}$ & $c_{21}$ & $c_{22}$ & $c_{23}$ & $c_{21}$ & $c_{22}$ & $c_{23}$ & $c_{21}$ & $c_{22}$ & $c_{23}$ & \\
\hline$c_{21}$ & & & $\mathrm{M}$ & & & $\mathrm{E}$ & & & $\mathrm{M}$ & {$[0.2279,0.3632,0.3632]$} \\
$c_{22}$ & $\mathrm{I}$ & & $\mathrm{QI}$ & $\mathrm{QI}$ & & $\mathrm{I}$ & $\mathrm{I}$ & & $\mathrm{I}$ & {$[0.6656,0.3551,0.3549]$} \\
$c_{23}$ & & & & & & & & & & {$[0.1066,0.2816,0.2819]$} \\
\hline
\end{tabular}

Tab.A7 Experts' pairwise comparison matrix of sub-criteria in safety about equipment reliability

\begin{tabular}{|c|c|c|c|c|c|c|c|c|c|c|}
\hline \multirow{2}{*}{$c_{34}$} & \multicolumn{3}{|c|}{ Expert 1} & \multicolumn{3}{|c|}{ Expert 2} & \multicolumn{3}{|c|}{ Expert 3} & \multirow{2}{*}{ Cloud weight } \\
\hline & $c_{21}$ & $c_{22}$ & $c_{23}$ & $c_{21}$ & $c_{22}$ & $c_{23}$ & $c_{21}$ & $c_{22}$ & $c_{23}$ & \\
\hline$c_{21}$ & & & & & & & & & & {$[0.0992,0.2792,0.2788]$} \\
\hline$c_{22}$ & QI & & I & I & & QI & I & & I & {$[0.6764,0.3521,0.3522]$} \\
\hline$c_{23}$ & MI & & & M & & & $\mathrm{E}$ & & & {$[0.2244,0.3687,0.3690]$} \\
\hline
\end{tabular}

Tab.A8 Experts' pairwise comparison matrix of sub-criteria in safety about resources waste

\begin{tabular}{ccccccccccc}
\hline & \multicolumn{3}{c}{ Expert 1 } & \multicolumn{5}{c}{ Expert 2 } & \multicolumn{3}{c}{ Expert 3 } & Cloud weight \\
\cline { 2 - 8 } & $c_{21}$ & $c_{22}$ & $c_{23}$ & $c_{21}$ & $c_{22}$ & $c_{23}$ & $c_{21}$ & $c_{22}$ & $c_{23}$ & \\
\hline$c_{21}$ & & & $\mathrm{M}$ & & & $\mathrm{M}$ & & & $\mathrm{MI}$ & {$[0.2403,0.3525,0.3523]$} \\
$c_{22}$ & $\mathrm{MI}$ & & $\mathrm{I}$ & $\mathrm{I}$ & & $\mathrm{I}$ & $\mathrm{I}$ & & $\mathrm{I}$ & {$[0.6506,0.3788,0.3786]$} \\
$c_{23}$ & & & & & & & & & & {$[0.1091,0.2688,0.2691]$} \\
\hline
\end{tabular}

Tab.A9 Experts' pairwise comparison matrix of sub-criteria in safety about personnel technical requirements

\begin{tabular}{lcccccccccc}
\hline & & & Expert 1 & \multicolumn{1}{c}{ Expert 2 } & & Expert 3 & Cloud weight \\
\cline { 2 - 8 }$c_{41}$ & $c_{21}$ & $c_{22}$ & $c_{23}$ & $c_{21}$ & $c_{22}$ & $c_{23}$ & $c_{21}$ & $c_{22}$ & $c_{23}$ & \\
\hline$c_{21}$ & & & & & & & & & & {$[0.1062,0.2310,0.2311]$} \\
$c_{22}$ & MI & & $\mathrm{M}$ & $\mathrm{MI}$ & & $\mathrm{I}$ & $\mathrm{M}$ & & $\mathrm{I}$ & {$[0.4215,0.4044,0.4043]$} \\
$c_{23}$ & $\mathrm{E}$ & & & $\mathrm{E}$ & & & $\mathrm{E}$ & & & {$[0.4215,0.4044,0.4043]$} \\
\hline
\end{tabular}

Tab.A10 Experts' pairwise comparison matrix of sub-criteria in safety about maintenance time

\begin{tabular}{|c|c|c|c|c|c|c|c|c|c|c|}
\hline \multirow{2}{*}{$c_{42}$} & \multicolumn{3}{|c|}{ Expert 1} & \multicolumn{3}{|c|}{ Expert 2} & \multicolumn{3}{|c|}{ Expert 3} & \multirow{2}{*}{ Cloud weight } \\
\hline & $c_{21}$ & $c_{22}$ & $c_{23}$ & $c_{21}$ & $c_{22}$ & $c_{23}$ & $c_{21}$ & $c_{22}$ & $c_{23}$ & \\
\hline$c_{21}$ & & & $\mathrm{E}$ & & & E & & & M & {$[0.2203,0.3636,0.3636]$} \\
\hline$c_{22}$ & M & & I & I & & QI & QI & & SI & {$[0.6729,0.3540,0.3541]$} \\
\hline$c_{23}$ & & & & & & & & & & {$[0.1068,0.2824,0.2823]$} \\
\hline
\end{tabular}


Tab.A11 Experts' pairwise comparison matrix of sub-criteria in safety about operational complexity

\begin{tabular}{ccccccccccc}
\hline & \multicolumn{3}{c}{ Expert 1 } & \multicolumn{3}{c}{ Expert 2 } & \multicolumn{3}{c}{ Expert 3 } & Cloud weight \\
\cline { 2 - 8 }$c_{43}$ & $c_{21}$ & $c_{22}$ & $c_{23}$ & $c_{21}$ & $c_{22}$ & $c_{23}$ & $c_{21}$ & $c_{22}$ & $c_{23}$ & \\
\hline$c_{21}$ & & $\mathrm{E}$ & $\mathrm{E}$ & & $\mathrm{E}$ & $\mathrm{E}$ & & $\mathrm{M}$ & $\mathrm{E}$ & {$[0.5609,0.4108,0.4107]$} \\
$c_{22}$ & & & & & & & & & {$[0.1457,0.2555,0.2556]$} \\
$c_{23}$ & & $\mathrm{M}$ & & & $\mathrm{E}$ & & & $\mathrm{E}$ & & {$[0.2934,0.3337,0.3337]$} \\
\hline
\end{tabular}

Tab.A12 Experts' pairwise comparison matrix of sub-criteria in safety about technical reliability

\begin{tabular}{ccccccccccc}
\hline & \multicolumn{3}{c}{ Expert 1 } & \multicolumn{3}{c}{ Expert 2 } & \multicolumn{3}{c}{ Expert 3 } & Cloud weight \\
\cline { 2 - 9 } & $c_{21}$ & $c_{22}$ & $c_{23}$ & $c_{21}$ & $c_{22}$ & $c_{23}$ & $c_{21}$ & $c_{22}$ & $c_{23}$ & \\
\hline$c_{21}$ & & $\mathrm{E}$ & & & $\mathrm{E}$ & & & $\mathrm{M}$ & & {$[0.3357,0.3332,0.3332]$} \\
$c_{22}$ & & & $\mathrm{E}$ & & & $\mathrm{E}$ & & & $\mathrm{E}$ & {$[0.3333,0.3352,0.3353]$} \\
$c_{23}$ & $\mathrm{E}$ & & & $\mathrm{E}$ & & & $\mathrm{E}$ & & & {$[0.3333,0.3352,0.3353]$} \\
\hline
\end{tabular}

Tab.A13 Experts' pairwise comparison matrix of sub-criteria in safety about budget

\begin{tabular}{|c|c|c|c|c|c|c|c|c|c|c|}
\hline \multirow{2}{*}{$c_{45}$} & \multicolumn{3}{|c|}{ Expert 1} & \multicolumn{3}{|c|}{ Expert 2} & \multicolumn{3}{|c|}{ Expert 3} & \multirow{2}{*}{ Cloud weight } \\
\hline & $c_{21}$ & $c_{22}$ & $c_{23}$ & $c_{21}$ & $c_{22}$ & $c_{23}$ & $c_{21}$ & $c_{22}$ & $c_{23}$ & \\
\hline$c_{21}$ & & & E & & & E & & & $\mathrm{E}$ & {$[0.2500,0.3549,0.3550]$} \\
\hline$c_{22}$ & M & & MI & MI & & I & M & & I & {$[0.6268,0.3726,0.3725]$} \\
\hline$c_{23}$ & & & & & & & & & & {$[0.1232,0.2724,0.2725]$} \\
\hline
\end{tabular}

Tab.B1 Experts' pairwise comparison matrix of sub-criteria in cost about personnel

\begin{tabular}{ccccccccccc}
\hline & \multicolumn{3}{c}{ Expert 1 } & \multicolumn{5}{c}{ Expert 2 } & \multicolumn{3}{c}{ Expert 3 } & Cloud weight \\
\cline { 2 - 8 } & $c_{11}$ & $c_{12}$ & $c_{13}$ & $c_{11}$ & $c_{12}$ & $c_{13}$ & $c_{11}$ & $c_{12}$ & $c_{13}$ & \\
\hline$c_{11}$ & & MI & & & M & & & M & & {$[0.2283,0.3590,0.3592]$} \\
$c_{12}$ & & & & & & & & & & {$[0.0967,0.2672,0.2670]$} \\
$c_{13}$ & $\mathrm{I}$ & QI & & I & SI & & I & I & & {$[0.6749,0.3738,0.3737]$} \\
\hline
\end{tabular}

Tab.B2 Experts' pairwise comparison matrix of sub-criteria in cost about facilities

\begin{tabular}{|c|c|c|c|c|c|c|c|c|c|c|}
\hline \multirow{2}{*}{$c_{22}$} & \multicolumn{3}{|c|}{ Expert 1} & \multicolumn{3}{|c|}{ Expert 2} & \multicolumn{3}{|c|}{ Expert 3} & \multirow{2}{*}{ Cloud weight } \\
\hline & $c_{11}$ & $c_{12}$ & $c_{13}$ & $c_{11}$ & $c_{12}$ & $c_{13}$ & $c_{11}$ & $c_{12}$ & $c_{13}$ & \\
\hline$c_{11}$ & & QI & I & & QI & I & & I & MI & {$[0.6711,0.3681,0.3680]$} \\
\hline$c_{12}$ & & & & & & & & & & {$[0.0989,0.2697,0.2700]$} \\
\hline$c_{13}$ & & M & & & M & & & MI & & {$[0.2300,0.3622,0.3620]$} \\
\hline
\end{tabular}


Tab.B3 Experts' pairwise comparison matrix of sub-criteria in cost about environment

\begin{tabular}{ccccccccccc}
\hline & \multicolumn{3}{c}{ Expert 1 } & \multicolumn{5}{c}{ Expert 2 } & \multicolumn{3}{c}{ Expert 3 } & Cloud weight \\
\cline { 2 - 9 } & $c_{11}$ & $c_{12}$ & $c_{13}$ & $c_{11}$ & $c_{12}$ & $c_{13}$ & $c_{11}$ & $c_{12}$ & $c_{13}$ & \\
\hline$c_{11}$ & & $\mathrm{M}$ & & & $\mathrm{E}$ & & & $\mathrm{M}$ & & {$[0.3376,0.3183,0.3183]$} \\
$c_{12}$ & & & $\mathrm{M}$ & & & $\mathrm{E}$ & & & $\mathrm{E}$ & {$[0.3183,0.3343,0.3341]$} \\
$c_{13}$ & $\mathrm{E}$ & & & $\mathrm{M}$ & & & $\mathrm{M}$ & & & {$[0.3441,0.3474,0.3475]$} \\
\hline
\end{tabular}

Tab.B4 Experts' pairwise comparison matrix of sub-criteria in cost about product quality

\begin{tabular}{|c|c|c|c|c|c|c|c|c|c|c|}
\hline \multirow{2}{*}{$c_{31}$} & \multicolumn{3}{|c|}{ Expert 1} & \multicolumn{3}{|c|}{ Expert 2} & \multicolumn{3}{|c|}{ Expert 3} & \multirow{2}{*}{ Cloud weight } \\
\hline & $c_{11}$ & $c_{12}$ & $c_{13}$ & $c_{11}$ & $c_{12}$ & $c_{13}$ & $c_{11}$ & $c_{12}$ & $c_{13}$ & \\
\hline$c_{11}$ & & VI & & & VI & & & SI & & {$[0.2749,0.3340,0.3340]$} \\
\hline$c_{12}$ & & & & & & & & & & {$[0.0794,0.2211,0.2206]$} \\
\hline$c_{13}$ & MI & VI & & MI & VI & & I & VI & & {$[0.6457,0.4449,0.4455]$} \\
\hline
\end{tabular}

Tab.B5 Experts' pairwise comparison matrix of sub-criteria in cost about spare parts requirements

\begin{tabular}{|c|c|c|c|c|c|c|c|c|c|c|}
\hline \multirow{2}{*}{$c_{32}$} & \multicolumn{3}{|c|}{ Expert 1} & \multicolumn{3}{|c|}{ Expert 2} & \multicolumn{3}{|c|}{ Expert 3} & \multirow{2}{*}{ Cloud weight } \\
\hline & $c_{11}$ & $c_{12}$ & $c_{13}$ & $c_{11}$ & $c_{12}$ & $c_{13}$ & $c_{11}$ & $c_{12}$ & $c_{13}$ & \\
\hline$c_{11}$ & & I & QI & & QI & QI & & M & M & {$[0.6772,0.3469,0.3468]$} \\
\hline$c_{12}$ & & & $\mathrm{E}$ & & & MI & & & $\mathrm{E}$ & {$[0.2166,0.3662,0.3661]$} \\
\hline$c_{13}$ & & & & & & & & & & {$[0.1062,0.2869,0.2871]$} \\
\hline
\end{tabular}

Tab.B6 Experts' pairwise comparison matrix of sub-criteria in cost about production loss

\begin{tabular}{|c|c|c|c|c|c|c|c|c|c|c|}
\hline \multirow{2}{*}{$c_{33}$} & \multicolumn{3}{|c|}{ Expert 1} & \multicolumn{3}{|c|}{ Expert 2} & \multicolumn{3}{|c|}{ Expert 3} & \multirow{2}{*}{ Cloud weight } \\
\hline & $c_{11}$ & $c_{12}$ & $c_{13}$ & $c_{11}$ & $c_{12}$ & $c_{13}$ & $c_{11}$ & $c_{12}$ & $c_{13}$ & \\
\hline$c_{11}$ & & M & $\mathrm{E}$ & & MI & $\mathrm{E}$ & & MI & M & {$[0.5736,0.4312,0.4313]$} \\
\hline$c_{12}$ & & & & & & & & & & {$[0.1275,0.2229,0.2228]$} \\
\hline$c_{13}$ & & MI & & & M & & & M & & {$[0.2989,0.3460,0.3459]$} \\
\hline
\end{tabular}

Tab.B7 Experts' pairwise comparison matrix of sub-criteria in cost about equipment reliability

\begin{tabular}{|c|c|c|c|c|c|c|c|c|c|c|}
\hline \multirow{2}{*}{$c_{34}$} & \multicolumn{3}{|c|}{ Expert 1} & \multicolumn{3}{|c|}{ Expert 2} & \multicolumn{3}{|c|}{ Expert 3} & \multirow{2}{*}{ Cloud weight } \\
\hline & $c_{11}$ & $c_{12}$ & $c_{13}$ & $c_{11}$ & $c_{12}$ & $c_{13}$ & $c_{11}$ & $c_{12}$ & $c_{13}$ & \\
\hline$c_{11}$ & & I & M & & QI & $\mathrm{E}$ & & I & MI & {$[0.6221,0.4299,0.4302]$} \\
\hline$c_{12}$ & & & & & & & & & & {$[0.1099,0.2223,0.2219]$} \\
\hline$c_{13}$ & & MI & & & $\mathrm{N}$ & & & M & & {$[0.2680,0.3477,0.3478]$} \\
\hline
\end{tabular}

Tab.B8 Experts' pairwise comparison matrix of sub-criteria in cost about resources waste

\begin{tabular}{lcccccccccc}
\hline & \multicolumn{3}{c}{ Expert 1 } & \multicolumn{5}{c}{ Expert 2 } & \multicolumn{3}{c}{ Expert 3 } & Cloud weight \\
\cline { 2 - 9 } & $c_{11}$ & $c_{12}$ & $c_{13}$ & $c_{11}$ & $c_{12}$ & $c_{13}$ & $c_{11}$ & $c_{12}$ & $c_{13}$ & \\
\hline$c_{11}$ & & & & & & & & & & \\
$c_{12}$ & $\mathrm{M}$ & & $\mathrm{M}$ & $\mathrm{M}$ & & $\mathrm{E}$ & $\mathrm{MI}$ & & $\mathrm{M}$ & {$[0.1250,0.2467,0.2466]$} \\
$c_{13}$ & $\mathrm{MI}$ & & & $\mathrm{M}$ & & & $\mathrm{M}$ & & & {$[0.5962,0.4198,0.4198]$} \\
\end{tabular}


Tab.B9 Experts' pairwise comparison matrix of sub-criteria in cost about personnel technical requirements

\begin{tabular}{ccccccccccc}
\hline & \multicolumn{3}{c}{ Expert 1 } & \multicolumn{3}{c}{ Expert 2 } & \multicolumn{3}{c}{ Expert 3 } & Cloud weight \\
\cline { 2 - 9 } & $c_{11}$ & $c_{12}$ & $c_{13}$ & $c_{11}$ & $c_{12}$ & $c_{13}$ & $c_{11}$ & $c_{12}$ & $c_{13}$ & \\
\hline$c_{11}$ & & & & & & & & & & {$[0.1211,0.2429,0.2428]$} \\
$c_{12}$ & $\mathrm{M}$ & & & $\mathrm{M}$ & & & $\mathrm{E}$ & & & {$[0.2713,0.3413,0.3414]$} \\
$c_{13}$ & $\mathrm{MI}$ & $\mathrm{M}$ & & $\mathrm{I}$ & $\mathrm{M}$ & & $\mathrm{M}$ & $\mathrm{E}$ & & {$[0.6077,0.4158,0.4159]$} \\
\hline
\end{tabular}

Tab.B10 Experts' pairwise comparison matrix of sub-criteria in cost about maintenance time

\begin{tabular}{ccccccccccc}
\hline & \multicolumn{3}{c}{ Expert 1 } & \multicolumn{3}{c}{ Expert 2 } & \multicolumn{3}{c}{ Expert 3 } & Cloud weight \\
\cline { 2 - 9 } & $c_{11}$ & $c_{12}$ & $c_{13}$ & $c_{11}$ & $c_{12}$ & $c_{13}$ & $c_{11}$ & $c_{12}$ & $c_{13}$ & \\
\hline$c_{11}$ & & & & & & & & & & {$[0.1166,0.1947,0.1950]$} \\
$c_{12}$ & MI & & & MI & & & M & & & {$[0.2973,0.3585,0.3585]$} \\
$c_{13}$ & $\mathrm{I}$ & $\mathrm{E}$ & & $\mathrm{MI}$ & $\mathrm{M} /$ & & $\mathrm{MI}$ & $\mathrm{E}$ & & {$[0.5860,0.4469,0.4465]$} \\
\hline
\end{tabular}

Tab.B11 Experts' pairwise comparison matrix of sub-criteria in cost about operational complexity

\begin{tabular}{ccccccccccc}
\hline & \multicolumn{3}{c}{ Expert 1 } & \multicolumn{5}{c}{ Expert 2 } & \multicolumn{3}{c}{ Expert 3 } & Cloud weight \\
\cline { 2 - 9 } & $c_{11}$ & $c_{12}$ & $c_{13}$ & $c_{11}$ & $c_{12}$ & $c_{13}$ & $c_{11}$ & $c_{12}$ & $c_{13}$ & \\
\hline$c_{11}$ & & $\mathrm{M}$ & & & $\mathrm{E}$ & & & $\mathrm{E}$ & & {$[0.3411,0.3291,0.3291]$} \\
$c_{12}$ & & & $\mathrm{E}$ & & & $\mathrm{E}$ & & & $\mathrm{E}$ & {$[0.3221,0.3282,0.3282]$} \\
$c_{13}$ & $\mathrm{E}$ & & & $\mathrm{M}$ & & & $\mathrm{E}$ & & & {$[0.3368,0.3427,0.3427]$} \\
\hline
\end{tabular}

Tab.B12 Experts' pairwise comparison matrix of sub-criteria in cost about technical reliability

\begin{tabular}{ccccccccccc}
\hline & \multicolumn{3}{c}{ Expert 1 } & \multicolumn{3}{c}{ Expert 2 } & \multicolumn{3}{c}{ Expert 3 } & Cloud weight \\
\cline { 2 - 9 } & $c_{11}$ & $c_{12}$ & $c_{13}$ & $c_{11}$ & $c_{12}$ & $c_{13}$ & $c_{11}$ & $c_{12}$ & $c_{13}$ & \\
\hline$c_{11}$ & & $\mathrm{M}$ & & & $\mathrm{E}$ & & & $\mathrm{E}$ & & {$[0.2625,0.3374,0.3374]$} \\
$c_{12}$ & & & & & & & & & & {$[0.1337,0.2699,0.2701]$} \\
$c_{13}$ & $\mathrm{M}$ & $\mathrm{M}$ & & $\mathrm{MI}$ & $\mathrm{M}$ & & $\mathrm{M}$ & $\mathrm{MI}$ & & {$[0.6038,0.3927,0.3925]$} \\
\hline
\end{tabular}

Tab.B13 Experts' pairwise comparison matrix of sub-criteria in cost about budget

\begin{tabular}{ccccccccccc}
\hline & \multicolumn{3}{c}{ Expert 1 } & \multicolumn{5}{c}{ Expert 2 } & \multicolumn{3}{c}{ Expert 3 } & Cloud weight \\
\cline { 2 - 8 } & $c_{11}$ & $c_{12}$ & $c_{13}$ & $c_{11}$ & $c_{12}$ & $c_{13}$ & $c_{11}$ & $c_{12}$ & $c_{13}$ & \\
\hline$c_{11}$ & & $\mathrm{MI}$ & $\mathrm{MI}$ & & $\mathrm{M}$ & $\mathrm{MI}$ & & $\mathrm{M}$ & $\mathrm{I}$ & {$[0.6174,0.4051,0.4053]$} \\
$c_{12}$ & & & $\mathrm{M}$ & & & $\mathrm{E}$ & & & $\mathrm{M}$ & {$[0.2637,0.3446,0.3443]$} \\
$c_{13}$ & & & & & & & & & & {$[0.1189,0.2503,0.2504]$} \\
\hline
\end{tabular}


Tab.C1 Experts' pairwise comparison matrix of sub-criteria in added value about hardware

\begin{tabular}{|c|c|c|c|c|c|c|c|c|c|c|c|c|c|c|c|c|}
\hline \multirow{2}{*}{$c_{11}$} & \multicolumn{5}{|c|}{ Expert 1} & \multicolumn{5}{|c|}{ Expert 2} & \multicolumn{5}{|c|}{ Expert 3} & \multirow{2}{*}{ Cloud weight } \\
\hline & $c_{31}$ & $c_{32}$ & $c_{33}$ & $c_{34}$ & $c_{35}$ & $c_{31}$ & $c_{32}$ & $c_{33}$ & $c_{34}$ & $c_{35}$ & $c_{31}$ & $c_{32}$ & $c_{33}$ & $c_{34}$ & $c_{35}$ & \\
\hline$c_{31}$ & & & M & $\mathrm{E}$ & M & & & M & M & E & & & M & $\mathrm{E}$ & E & {$[0.2633,0.2134,0.2133]$} \\
\hline$c_{32}$ & M & & M & & MI & M & & M & & M & M & & MI & & $\mathrm{E}$ & {$[0.2881,0.2131,0.2131]$} \\
\hline$c_{33}$ & & & & & & & & & & & & & & & & {$[0.0743,0.1681,0.1681]$} \\
\hline$c_{34}$ & & E & $\mathrm{E}$ & & $\mathrm{M}$ & & M & $\mathrm{E}$ & & E & & E & M & & $\mathrm{E}$ & {$[0.2636,0.2236,0.2236]$} \\
\hline$c_{35}$ & & & $\mathrm{E}$ & & & & & M & & & & & $\mathrm{E}$ & & & {$[0.1107,0.1818,0.1818]$} \\
\hline
\end{tabular}

Tab.C1 Experts' pairwise comparison matrix of sub-criteria in added value about software

\begin{tabular}{|c|c|c|c|c|c|c|c|c|c|c|c|c|c|c|c|c|}
\hline \multirow{2}{*}{$c_{12}$} & \multicolumn{5}{|c|}{ Expert 1} & \multicolumn{5}{|c|}{ Expert 2} & \multicolumn{5}{|c|}{ Expert 3} & \multirow{2}{*}{ Cloud weight } \\
\hline & $c_{31}$ & $c_{32}$ & $c_{33}$ & $c_{34}$ & $c_{35}$ & $c_{31}$ & $c_{32}$ & $c_{33}$ & $c_{34}$ & $c_{35}$ & $c_{31}$ & $c_{32}$ & $c_{33}$ & $c_{34}$ & $c_{35}$ & \\
\hline$c_{31}$ & & & & & & & & & & & & & & & & {$[0.0685,0.1634,0.1634]$} \\
\hline$c_{32}$ & MI & & M & & & M & & E & & & E & & M & & & {$[0.1723,0.1980,0.1980]$} \\
\hline$c_{33}$ & $\mathrm{E}$ & & & & & M & & & & & E & & & & & {$[0.1054,0.1834,0.1833]$} \\
\hline$c_{34}$ & M & M & MI & & MI & E & M & E & & MI & M & E & M & & E & {$[0.4026,0.2323,0.2323]$} \\
\hline$c_{35}$ & M & E & E & & & M & $\mathrm{E}$ & E & & & E & E & M & & & {$[0.2511,0.2230,0.2230]$} \\
\hline
\end{tabular}

Tab.C1 Experts' pairwise comparison matrix of sub-criteria in added value about personnel training

\begin{tabular}{|c|c|c|c|c|c|c|c|c|c|c|c|c|c|c|c|c|}
\hline \multirow{2}{*}{$c_{13}$} & \multicolumn{5}{|c|}{ Expert 1} & \multicolumn{5}{|c|}{ Expert 2} & \multicolumn{5}{|c|}{ Expert 3} & \multirow{2}{*}{ Cloud weight } \\
\hline & $c_{31}$ & $c_{32}$ & $c_{33}$ & $c_{34}$ & $c_{35}$ & $c_{31}$ & $c_{32}$ & $c_{33}$ & $c_{34}$ & $c_{35}$ & $c_{31}$ & $c_{32}$ & $c_{33}$ & $c_{34}$ & $c_{35}$ & \\
\hline$c_{31}$ & & $\mathrm{E}$ & $\mathrm{E}$ & $\mathrm{E}$ & M & & $\mathrm{E}$ & $\mathrm{E}$ & M & M & & M & M & $\mathrm{E}$ & $\mathrm{E}$ & {$[0.3871,0.2308,0.2308$} \\
\hline$c_{32}$ & & & $\mathrm{E}$ & $\mathrm{E}$ & $\mathrm{E}$ & & & $\mathrm{E}$ & M & $\mathrm{E}$ & & & $\mathrm{E}$ & $\mathrm{E}$ & M & {$[0.2522,0.2164,0.2163$} \\
\hline$c_{33}$ & & & & $\mathrm{E}$ & $\mathrm{E}$ & & & & $\mathrm{E}$ & $\mathrm{E}$ & & & & $\mathrm{E}$ & $\mathrm{E}$ & {$[0.1698,0.2012,0.2012$} \\
\hline$c_{34}$ & & & & & $\mathrm{E}$ & & & & & EM & & & & & $\mathrm{E}$ & {$[0.1154,0.1845,0.1846$} \\
\hline$c_{35}$ & & & & & & & & & & & & & & & & {$[0.0755,0.1670,0.1670$} \\
\hline
\end{tabular}

Tab.D1 Experts' pairwise comparison matrix of sub-criteria in feasibility about hardware

\begin{tabular}{|c|c|c|c|c|c|c|c|c|c|c|c|c|c|c|c|c|}
\hline \multirow{2}{*}{$c_{11}$} & \multicolumn{5}{|c|}{ Expert 1} & \multicolumn{5}{|c|}{ Expert 2} & \multicolumn{5}{|c|}{ Expert 3} & \multirow{2}{*}{ Cloud weight } \\
\hline & $c_{41}$ & $c_{42}$ & $c_{43}$ & $c_{44}$ & $c_{45}$ & $c_{41}$ & $c_{42}$ & $c_{43}$ & $c_{44}$ & $c_{45}$ & $c_{41}$ & $c_{42}$ & $c_{43}$ & $c_{44}$ & $c_{45}$ & \\
\hline$c_{41}$ & & $\mathrm{E}$ & & & M & & M & & & E & & M & & & $\mathrm{E}$ & {$[0.1560,0.2068,0.2068]$} \\
\hline$c_{42}$ & & & & & E & & & & & E & & & & & $\mathrm{E}$ & {$[0.0996,0.1864,0.1864]$} \\
\hline$c_{43}$ & M & M & & & M & E & M & & & M & E & M & & & M & {$[0.2487,0.2161,0.2160]$} \\
\hline$c_{44}$ & M & MI & M & & I & MI & MI & M & & MI & MI & MI & M & & MI & {$[0.4290,0.2202,0.2201]$} \\
\hline$c_{45}$ & & & & & & & & & & & & & & & & {$[0.0666,0.1706,0.1706]$} \\
\hline
\end{tabular}


Tab.D2 Experts' pairwise comparison matrix of sub-criteria in feasibility about software

\begin{tabular}{|c|c|c|c|c|c|c|c|c|c|c|c|c|c|c|c|c|}
\hline \multirow{2}{*}{$c_{12}$} & \multicolumn{5}{|c|}{ Expert 1} & \multicolumn{5}{|c|}{ Expert 2} & \multicolumn{5}{|c|}{ Expert 3} & \multirow{2}{*}{ Cloud weight } \\
\hline & $c_{41}$ & $c_{42}$ & $c_{43}$ & $c_{44}$ & $c_{45}$ & $c_{41}$ & $c_{42}$ & $c_{43}$ & $c_{44}$ & $c_{45}$ & $c_{41}$ & $c_{42}$ & $c_{43}$ & $c_{44}$ & $c_{45}$ & \\
\hline$c_{41}$ & & & & E & E & & & & E & E & & & & M & M & {$[0.1573,0.1969,0.1969]$} \\
\hline$c_{42}$ & M & & $\mathrm{E}$ & I & M & E & & M & M & M & E & & E & M & M & {$[0.4093,0.2280,0.2280]$} \\
\hline$c_{43}$ & E & & & M & E & M & & & E & M & M & & & E & E & {$[0.2543,0.2193,0.2194]$} \\
\hline$c_{44}$ & & & & & E & & & & & E & & & & & E & {$[0.1058,0.1839,0.1839]$} \\
\hline$c_{45}$ & & & & & & & & & & & & & & & & {$[0.0733,0.1719,0.1719]$} \\
\hline
\end{tabular}

Tab.D3 Experts' pairwise comparison matrix of sub-criteria in feasibility about personnel training

\begin{tabular}{|c|c|c|c|c|c|c|c|c|c|c|c|c|c|c|c|c|}
\hline \multirow{2}{*}{$c_{13}$} & \multicolumn{5}{|c|}{ Expert 1} & \multicolumn{5}{|c|}{ Expert 2} & \multicolumn{5}{|c|}{ Expert 3} & \multirow{2}{*}{ Cloud weight } \\
\hline & $c_{41}$ & $c_{42}$ & $c_{43}$ & $c_{44}$ & $c_{45}$ & $c_{41}$ & $c_{42}$ & $c_{43}$ & $c_{44}$ & $c_{45}$ & $c_{41}$ & $c_{42}$ & $c_{43}$ & $c_{44}$ & $c_{45}$ & \\
\hline$c_{41}$ & & & M & & M & & & E & & E & & & E & & E & {$[0.1590,0.2056,0.2056]$} \\
\hline$c_{42}$ & MI & & MI & M & M & M & & MI & M & MI & E & & M & $\mathrm{E}$ & M & {$[0.4209,0.2254,0.2254]$} \\
\hline$c_{43}$ & & & & & E & & & & & E & & & & & E & {$[0.0982,0.1816,0.1816]$} \\
\hline$c_{44}$ & M & & M & & M & E & & M & & $\mathrm{M}$ & E & & E & & M & {$[0.2527,0.2156,0.2156]$} \\
\hline$c_{45}$ & & & & & & & & & & & & & & & & {$[0.0692,0.1717,0.1718]$} \\
\hline
\end{tabular}

